\title{
Los artistas del Códice Laud: el enigma de su origen
}

\section{The Origin of Codex Laud's Artists: An Enigma}

Artículo recibido el I8 de mayo de 2020; devuelto para revisión el 9 de junio de 2020; aceptado el 9 de diciembre de 2020; https://doi.org/IO.2220I/iie.I8703062e.202I.II8.2745.

María Isabel Álvarez Universidad Nacional Autónoma de México, Facultad de Filosofía y

Icaza Longoria Letras, marisa.alvarezicaza@gmail.com,

https://orcid.org/oooo-0002-852I-9364

Líneas de investigación Códices mesoamericanos; definición, origen y desarrollo de la tradición Mixteca-Puebla; definición de escuelas pictóricas del Posclásico; procedencia de los códices del Grupo Borgia; metodología para la definición y el análisis del estilo en el arte mesoamericano.

Lines of research Mesoamerican codices; definition, origin and development of the Mixteca-Puebla tradition; Postclassic pictorial schools; provenience of the "Borgia Group" codices; methodology for definition and analysis of style in Mesoamerican art.

Publicación más relevante "Variedades estilísticas de la tradición Mixteca-Puebla", Estilo y región en el arte mesoamericano, María Isabel Álvarez Icaza Longoria y Pablo Escalante Gonzalbo, eds. (Ciudad de México: Universidad Nacional Autónoma de México-Instituto de Investigaciones Estéticas, 2017), I77-I9I.

Resumen Este artículo es una síntesis de una investigación más amplia dedicada al Códice Laud que centra su atención en el problema de su procedencia e, indirectamente, en el del Grupo Borgia. Se presentan las cualidades estilísticas de este manuscrito pictográfico, incluidos sus materiales y técnica pictórica; se analizan los argumentos esgrimidos con anterioridad por otros investigadores sobre el enigma de su origen, y se muestran las comparaciones estilísticas e iconográficas entre el Laud y otras obras de arte - pintura mural, cerámica pintada, relieves y escultura-, de seis diferentes regiones de Mesoamérica. Por medio del análisis iconográfico se reconoce el Códice Laud como un documento pictográfico prehispánico náhuatl y se propone la región de Tehuacán como su lugar de origen. 
Palabras clave Códice Laud; Grupo Borgia; procedencia; códices mesoamericanos; escuelas pictóricas.

Abstract This article is a synthesis of broader research concerning the Codex Laud. It focuses on the problem of its provenance and, indirectly, on the "Borgia Group". It presents the stylistic qualities of this pictographic manuscript, including its materials and pictorial technique, and analyses the arguments offered by other researchers surrounding the enigma of its origin. It also presents stylistic and iconographic comparisons between the Codex Laud and other works of art-mural paintings, polychrome pottery, reliefs and sculptures—from six different Mesoamerican regions. Through an iconographic analysis the Codex Laud is recognized as a Nahuatl pre-Hispanic pictographic document and the Tehuacán region is proposed as its possible place of origin.

Keywords Codex Laud; Borgia Group; provenance; Mesoamerican codices; pictorial schools. 
DOI: https://doi.org/10.22201/iie.18703062e.2021.118.2745

\author{
MARÍA ISABEL ÁLVAREZ ICAZA LONGORIA \\ FACULTAD DE FILOSOFÍA Y LETRAS, UNAM
}

\title{
Los artistas del Códice Laud: el enigma de su origen
}

$\mathrm{E}$ 1 documento pictográfico mesoamericano que conocemos ahora con el nombre de Códice Laud se clasifica dentro del llamado Grupo Borgia, ${ }^{1}$ por su contenido calendárico-adivinatorio-ritual, y es uno de los más enigmáticos que han perdurado hasta nuestros días. La expresividad de sus formas, sus intensos y vivos colores, la precisión de su línea, sus misteriosos e impactantes mensajes han sorprendido e intrigado a quien lo conoce; posee una técnica de elaboración muy sofisticada y es uno de los manuscritos pictográficos antiguos de México mejor conservados. Pudo haberse elaborado entre el siglo xiv y antes de la llegada de los espańoles, tiempo en el que se manifiesta de forma madura la tradición Mixteca-Puebla; ${ }^{2}$ es decir, posiblemente hace unas siete centurias.

Entre los misterios que encierra esta sorprendente obra de arte están su lugar de origen y la filiación cultural de sus creadores; problema grave y común a todos los códices del Grupo Borgia, si tomamos en consideración que sólo son siete los documentos prehispánicos religiosos del centro y sur de México que sobreviven. En una investigación profunda sobre este tema ${ }^{3}$ presenté com-

I. El cual incluye además del Laud y el Fejérváry, el Borgia que le da nombre al grupo, el Cospi y Vaticano B. A este grupo se han sumado el Manuscrito No. 20 de Aubin y el Porfirio Díaz.

2. H. B. Nicholson, "Introduction", en Mixteca-Puebla Discoveries and Research in Mesoamerican Art and Archaeology, H. B. Nicholson y Eloise Quiñones, eds. (Culver City, Ca.: Labyrinthos, 1994), XI.

3. María Isabel Álvarez Icaza Longoria, "El Códice Laud, su tradición, su escuela, sus artistas”, tesis de doctorado en Historia del Arte (Ciudad de México: Universidad Nacional Autónoma 


\section{DOI: https://doi.org/10.22201/iie.18703062e.2021.118.2745}

I86

MARÍA ISABEL ÁLVAREZ ICAZA LONGORIA

paraciones estilísticas e iconográficas, con materiales arqueológicos de contexto conocido, de seis regiones propuestas como sus posibles lugares de origen. Analicé también los diferentes argumentos esgrimidos por los investigadores que han examinado el Códice Laud, así como los ejemplos aludidos para corroborar sus hipótesis sobre el lugar de procedencia designado por cada uno de estos estudios: el valle de Puebla-Tlaxcala, ${ }^{4}$ la Mixteca, ${ }^{5}$ valle de Tehuacán, ${ }^{6}$ la cuenca de México, ${ }^{7}$ la Mixtequilla (costa del Golfo) ${ }^{8}$ y la región cuicateca ${ }^{9}$ (La Cañada, en Oaxaca) (fig. I).

de México-Facultad de Filosofía y Letras, 20I4). Una síntesis en inglés sobre el tema de la procedencia puede consultarse en María Isabel Álvarez Icaza, "The Codex Laud and the Problem of its Provenience", en Mexican Manuscripts. New Scientific Approaches and Interpretation, Maarten Jansen, Virginia Lladó-Buisán y Ludo Snijders, eds. (Leiden: Koninklijke Brill NV, 2019), I75-2II.

4. Carlos Martínez Marín, El Códice Laud, introd., selección y notas (Ciudad de México: Instituto Nacional de Antropología e Historia, 196I); José Corona Núñez, Antigüedades de México, basadas en la recopilación de Lord Kingsborough (Ciudad de México: Secretaría de Hacienda y Crédito Público, 1964-1967); Manuel Carrera Stampa, "Códices, mapas y lienzos de la cultura náhuatl”, Estudios de Cultura Náhuatl, núm. 5 (1965): 165-220.

5. Donald Robertson, "The Mixtec Religious Manuscripts", en Ancient Oaxaca. Discoveries in Mexican Archeology and History, John Paddock (Stanford: Stanford University Press, 1966), 298-312; Elizabeth Boone, Cycles of Times and Meaning in the Mexican Books of Fate (Austin: University of Texas Press, 2007), 218.

6. Eduard Seler, Fejérváry-Mayer. An Old Mexican Picture Manuscript in the Liverpool Free Public Museum (I20I4/M), A. H. Keane, ed. (Berlín/Londres y Edimburgo: University Press, I9OI-1902), 4-5.

7. Francisco del Paso y Troncoso, Descripción, historia y exposición del códice pictórico de los antiguos náuas (Ciudad de México: Siglo XXI Editores, I979 [I898]), 58; Dúrdica Śégota, "El olvido de una memoria escrita. Los códices prehispánicos en las colecciones europeas", en México en el mundo de las colecciones de arte. Mesoamérica 2, Beatriz de la Fuente, coord. (Ciudad de México: Secretaría de Relaciones Exteriores-Universidad Nacional Autónoma de México-Consejo Nacional para la Cultura y las Artes, 1994), 286.

8. Cottie A. Burland, Codex Laud (Graz: Akademische Druck- u. Verlagsanstalt, 1966); H. B. Nicholson, "The Problem of the Provenience of the Members of the 'Codex Borgia Group': A Summary”, en Summa Anthropológica en homenaje a Roberto Weitlaner (Ciudad de México: Instituto Nacional de Antropología e Historia, 1966), I45-I58; Patricia Anawalt, "Costume Analysis and the Provenience of the Borgia Group Codices", American Antiquity 46, núm. 4 (I98I): 849.

9. Ferdinand Anders, Maarten Jansen y Alejandra Cruz Ortiz, Códice Laud. La pintura de la muerte y de los destinos, libro explicativo del Códice Laud (Ciudad de México-Graz: Fondo de Cultura Económica-Akademische Druck und Verlagsanstalt, 1994). Quedó fuera del presente estudio Malinalco señalado por Karl A. Nowotny como posible lugar de origen del Códice 


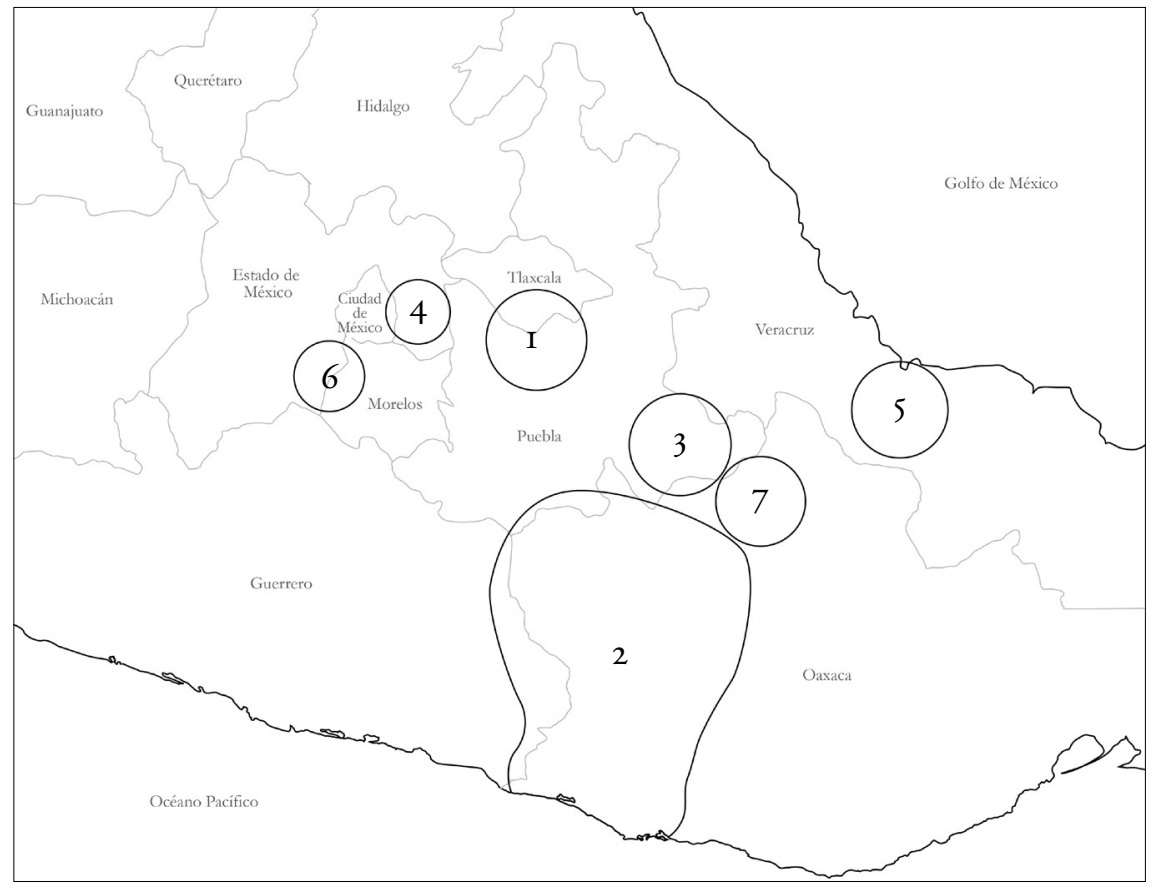

I. Mapa de las posibles zonas de procedencia del Códice Laud, según I) Martínez Marín, Corona Núnez y Carrera Stampa; 2) Robertson; 3) Seler; 4) Del Paso y Troncoso y Šégota; 5) Burland, Nicholson y Anawalt; 6) Nowotny; 7) Anders, Jansen y Cruz. Dibujo: Citlali Coronel.

Esta investigación me permitió identificar algunas cualidades del estilo y la iconografía de las regiones donde se desarrollaron diferentes "escuelas pictóricas", o variedades estilísticas, ${ }^{10}$ vinculadas a la tradición artística Mixteca-Pue-

Laud, debido a que hasta el momento no he localizado imágenes históricas de las pinturas que existieron en el recinto sagrado, sino sólo una reproducción, lo que impide hacer una comparación estilística. Karl A. Nowotny, Tlacuilloli Style and Content of the Mexican Pictorial Manuscripts with a Catalog of Borgia Group, George A. Everett y Edward Sisson, trads. y eds. (Norman: University of Oklahoma Press, 2005), 9.

ıo. María Isabel Álvarez Icaza Longoria, "Variedades estilísticas de la tradición Mixteca-Puebla”, en Estilo y región en el arte mesoamericano, M. I. Álvarez Icaza L. y Pablo Escalante Gonzalbo, coords. (Ciudad de México: Universidad Nacional Autónoma de México-Instituto de Investigaciones Estéticas, 2017), I77-I9I; Álvarez Icaza, "El Códice Laud, su tradición, su escuela, sus artistas", 26-63. 


\section{DOI: https://doi.org/10.22201/iie.18703062e.2021.118.2745}

bla, a la cual pertenecen los códices; ${ }^{\text {II }}$ y profundizar en el complejo problema de la procedencia de los manuscritos religiosos prehispánicos, en general, y del Códice Laud, en particular.

Esta tradición se conoce también como "estilo internacional del Posclásico", puesto que se manifiesta de manera extendida en buena parte del territorio mesoamericano en obras pictóricas y en relieves que presentan características comunes, pero también variaciones regionales o locales, durante el Posclásico Tardío (I35O-I52I d.C.). ${ }^{12}$ Si bien es cierto que esta tradición fue generalizada, no utilizo esta designación acuñada por Donald Robertson ${ }^{13}$ porque desdibuja el origen de la tradición Mixteca-Puebla que ubico junto con otros autores, en la región del valle Puebla-Tlaxcala.

\section{La historia del manuscrito pictográfico}

Como sucede con otros códices mesoamericanos, el nombre del documento que nos ocupa tiene poco que ver con sus creadores o con su lugar de origen; su designación se debe a que perteneció al arzobispo de Canterbury, Inglaterra, William Laud (I573-1645), quien lo donó en I636 a la Biblioteca Bodleiana, de la Universidad de Oxford. Lleva inscrita en la cubierta una leyenda en latín que lo identifica como su donador y antiguo dueño: "Liber Guil. Laudi Archiepi. Cant: et Cancellarij universit Oxon. I636", "Libro de Guillermo Laud Arzobispo de Cantebury y Canciller de la Universidad de Oxford, I636".

La forma en que salió de la Nueva España se desconoce; no obstante, existen varias hipótesis planteadas sobre cómo pudo adquirir William Laud el

II. Pablo Escalante, Los códices mesoamericanos antes y después de la conquista española (Ciudad de México: Fondo de Cultura Económica, 20I0), 35.

I2. H. B. Nicholson, "The Problem of the Provenience, I45-I58"; Michel Lind, "Cholulteca and Mixteca Polichromes: Two Mixteca-Puebla Regional Sub-Styles”, en Henry B. Nicholson y Eloise Quińones, eds., Mixteca-Puebla Discoveries and Research in Mesoamerican Art and Archaeology (Culver City, Ca.: Labyrinthos, 1994), 79-99; Eloise Quiñones Keber, "The Codex Style: Which Codex, Which Style?”, en Mixteca-Puebla Discoveries and Research in Mesoamerican Art and Archaeology, I43-I52.

I3. Donald Robertson, "The Tulum Murals: The International Style of the Late Post-Classic", en Congreso Internacional de Americanistas, sesión 38, vol. 2 (Stuttgart y Múnich, 1968), 77-88. 
manuscrito. Una apunta a que fue un obsequio del rey Carlos $I,{ }^{14}$ debido a que desde la infancia del príncipe el arzobispo era muy cercano a él y a George Villiers, duque de Buckingham. Este último y Carlos I habrían viajado a España en $1622,{ }^{15}$ tiempo en el que la monarquía inglesa estaba interesada en aliarse, vía matrimonial, con el reino español. El arzobispo fue colaborador cercano del monarca y un aficionado coleccionista de documentos, por lo cual es posible que lo haya recibido de manos de ellos. Otra posibilidad es que el códice haya sido entregado al duque de Buckingham en Inglaterra, por medio de dos embajadores del imperio español, antes de que los ingleses le declararan la guerra. En la correspondencia, catálogos ${ }^{16} \mathrm{y}$ en el propio diario $^{17}$ de William Laud, no se encuentra información de cómo lo adquirió y quizá nunca lo sabremos; eran tiempos de lucha por el control político de Inglaterra entre protestantes y católicos, lo que derivó en el apresamiento y ejecución del arzobispo. ${ }^{18}$

Hasta el día de hoy el Códice Laud sigue resguardado como Manuscrito Misceláneo No. 678, en la Biblioteca Bodleiana, si bien en los inventarios de W. Laud y en este repositorio se catalogó como un manuscrito egipcio.

\section{El estilo del Códice Laud}

En realidad, aunque esta atribución egipcia nos pudiera parecer extraña, tienen algo en común este arte y los códices mesoamericanos, especialmente con el Laud. Como señala Donald Robertson, ${ }^{19}$ "las formas de los signos en el

I4. Walter Lehman, "Les Peintures mixtéco-zapoteques et quelques documents apparentés", Journal de la Societé des Americanistes (1905): 258.

I5. William Laud, The Works of the Most Reverended Father in God, William Laud, D. D. sometime Archbishop of Canterbury, vol. III. Devotions, Diary, and History (Oxford: Henry Parker, 1853) (reimpresión Londres: St. Paul's Church Yard, I694), I35-I40.

16. Laud, The Works of the Most Reverended Father in God, I35-I40.

17. Archivo histórico, St. John's College, Oxford, Reino Unido, Diario de William Laud.

I8. Esta circunstancia afectó directa y fatalmente al arzobispo católico anglicano, quien se había convertido en el segundo hombre más importante de la política inglesa del rey Carlos I. Acusado de traición por los puritanos y luego por mal aconsejar al rey, pasó cuatro años en la cárcel de la Torre de Londres antes de morir en el cadalso en I645; como ocurriera después con el mismo monarca, cuando ese grupo tomó el poder bajo el liderazgo de Oliver Cromwell en la guerra civil inglesa.

19. D. Robertson construye su propuesta a partir de un modelo metodológico que adelanta 


\section{DOI: https://doi.org/10.22201/iie.18703062e.2021.118.2745}

190

MARÍA ISABEL ÁLVAREZ ICAZA LONGORIA

manuscrito están controladas por las mismas convenciones artísticas generales que regían a la Grecia y Egipto antiguos; íntimamente ligadas a una llamada escritura jeroglífica, que mejor ha de ser considerada un sistema de notación mnemónica, compuesto por símbolos o signos reunidos dado su valor simbólico". ${ }^{20}$ En este arte se privilegia la comunicación, se eligen imágenes simples sobre las complejas que transmiten mejor los mensajes y se fijan en la memoria. Otras afinidades estilísticas que señala Robertson entre las imágenes de estas culturas son: la figura humana como centro de las escenas; el predominio de la vista de perfil y la falta de correspondencia anatómica en pies y manos; el uso generalizado de yuxtaposición de planos — presenta simultáneamente dos vistas, perfil y frente o perfil y alzado-, así como la sobreposición de formas con la intención de dar profundidad, entre las estrategias de representación del espacio. ${ }^{21}$

En lo que se diferencian de los códices es que en el arte egipcio y griego la proporción de la figura humana, y en general la representación del mundo, es más naturalista; a diferencia de la compacta, simplificada y esquemática que se utiliza en los códices del México antiguo. Cualidad que al mismo tiempo coexiste, en estos últimos, con una aguda observación de la naturaleza que destaca lo que caracteriza a la persona, el objeto, animal, vegetal o símbolo, para distinguirlos, aunque de una forma estereotipada; sin dejar de privilegiar la transmisión del mensaje sobre la mímesis de la realidad. A su vez, en las obras pictóricas de todas estas culturas antiguas el color es plano, se aplica sin gradación de luz ni sombras; ${ }^{22}$ y la línea de contorno es común, si bien uno de los rasgos que la distingue en los códices es su cualidad uniforme y firme, para encerrar las formas y las áreas de color, por lo común a manera de contorno (en casos excepcionales esto no sucede así, como se verá).

Pablo Escalante, siguiendo esta misma línea de investigación, hace notar más cualidades que definen el estilo de los códices, como reducir las formas y

Emanuel Löwy en The Rendering of Nature in Early Greek Art, apud Mexican Manuscript Painting of the Early Colonial Period (New Haven: Yale University Press, 1959), 23.

20. Robertson, Mexican Manuscript Painting of the Early Colonial Period, 23-24. "The forms of the manuscript signs are controlled by the same general artistic conventions that governed Archaic Greece, Egypt, or even Contemporary primitive art [...] intimately tied to a so-called hieroglyphic writing (better considered as a system of mnemonic notations), they had to be composed of symbols or signs put together for their symbolic value alone".

21. Robertson, Mexican Manuscript Painting of the Early Colonial Period, 17-18.

22. Robertson, Mexican Manuscript Painting of the Early Colonial Period, 17-I8. 
la figura humana a estereotipos; la proporción de dos a cuatro cabezas en relación al tamaño del cuerpo, dependiendo del códice; la cabeza, las manos y los pies muy grandes; la oreja en forma esquemática y similar a un corte transversal de un hongo; las uñas suelen ser muy visibles; las sandalias, en particular la talonera y el lazo del tobillo son muy ostensibles; los pies se representan ligeramente más largos que las sandalias y se curvan hacia abajo. ${ }^{23}$

Si bien existen cualidades estilísticas comunes entre los códices mesoamericanos y las imágenes del mundo clásico antiguo, que permiten explicar la manera de la temprana recepción que tuvo el Códice Laud en Europa, son estas mismas cualidades, sus semejanzas estilísticas y temáticas, las que llevaron a Eduard Seler a agrupar al Códice Laud entre los códices del llamado Grupo Borgia, no obstante que presentan estilos diferentes; excepto el Laud y el Fejérváry que son reconocidos por todos sus estudiosos como un subgrupo por sus afinidades.

Algunos de los rasgos distintivos del Códice Laud, como la simplificación y la economía en la configuración de las formas, así como la clara tendencia a la geometrización, también los encontramos en el Códice Fejérváry. Otras cualidades estilísticas que caracterizan al Códice Laud son la precisión de la línea y las sutiles elecciones estéticas en torno a la forma y el color. Su ejecución revela manos maestras, artistas que se distinguen por la pulcritud de su técnica pictórica, el equilibrio en sus composiciones, el dinamismo y a veces el dramatismo de sus escenas, a pesar de posturas rígidas y estereotipadas. Un complejo código de significados en torno al color, a símbolos abstractos unívocos, insignias, tocados, vestimentas, adornos y marcas corporales diferencian a los personajes por género, edad, estatus, actividad — y otros distintivos cuyo significado desconocemos aún.

La forma abreviada y sintética en la que se presentan los temas dificulta la comprensión de su significado. Por ello, el entendimiento de su simbolismo ha sido un reto. Por ejemplo, para el Tonalpohualli sólo se muestran los veinte glifos de día, aunque se consideran de forma implícita los 260 por un sistema posicional de las columnas. En contraste con esto, se puede ver el despliegue de todos los días de forma extensa en los códices Borgia, Cospi y Vaticano B en una tabla de 52 columnas por cinco registros horizontales, gracias a lo cual se han podido hacer avances en el desciframiento del Códice Laud. Esto revela

23. Escalante, Los códices mesoamericanos, 49-5I. 


\section{DOI: https://doi.org/10.22201/iie.18703062e.2021.118.2745}

I92

que no sólo se trataba de saber pintar, sino de decirlo de forma sintética, lo cual implicó un conocimiento profundo de este calendario ritual.

La estructura calendárica de los códices, como lo demostró Karl A. Nowotny, ${ }^{24}$ brinda información sobre los capítulos, la organización de cada uno y los diferentes arreglos y combinaciones que tenían para este calendario. Entender lo anterior orienta en algo fundamental como reconocer el orden de lectura del Códice Laud, de derecha a izquierda, como antes lo hiciera notar Francisco del Paso y Troncoso, a finales de siglo XIX. ${ }^{25}$ En este tenor, el investigador austriaco pudo identificar II capítulos o secciones en los que se divide la estructura del Laud; ${ }^{26}$ los temas que trata influyen en la composición en cuadretes, y en las escenas que ocupan toda una lámina y no tienen división.

Como algunos estudiosos ${ }^{27}$ han hecho ver, en sus comparaciones con otros códices del Grupo Borgia, el Códice Laud tiene pocos capítulos paralelos con ellos. Como otras particularidades, se debe destacar que es el único códice donde Tláloc aparece como Patrono de los días y se dedica un capítulo completo a Tlazoltéotl (capítulo 9, láminas 39 a 42), como diosa del Tonalpohualli.

\section{Materiales y técnica pictórica}

Los pintores del Códice Laud, como los del resto del Grupo Borgia y los códices mixtecos, usaron piel animal curtida para obtener un soporte durable, firme y flexible a la vez. Se desconoce, por el momento, si los pintores mismos preparaban las pieles, o si había un oficio como talabartero, u otro artesano, que además de preparar la piel aplicara la base de preparación para conseguir una superficie plana y lisa sobre la cual dibujar y pintar.

24. Karl A. Nowotny, "Kommentar zum Codex Laud", tesis de doctorado (Viena: Facultad de Filosofía de la Universidad de Viena, 1939) y Karl A. Nowotny, Tlacuilli. Style and Content of the Mexican Pictorial Manuscripts with a Catalog of Borgia Group, George A. Everett y Edward Sisson, trads. y eds. (Norman: University of Oklahoma Press, 2005).

25. Del Paso y Troncoso, Descripción, historia y exposición.

26. Nowotny, "Kommentar zum Codex Laud".

27. John Glass y Donald Robertson, "A Census of Middle American Pictorial Manuscripts", en Handbook of Middle American Indians, Ethnohistorical Sources, vol. I4 (Austin: Texas Univesity Press, 1975), 8I-252; Brodo Spranz, Los dioses en los códices mexicanos del Grupo Borgia (Ciudad de México: Fondo de Cultura Económica, 1993 [1964]); Elizabeth Boone, Cycles of Times and Meaning in the Mexican Books of Fate (Austin: University of Texas Press, 2007). 


\section{DOI: https://doi.org/10.22201/iie.18703062e.2021.118.2745}

LOS ARTISTAS DEL CÓDICE LAUD: EL ENIGMA DE SU ORIGEN

El códice que aquí se estudia consta de cuatro segmentos de piel, presumiblemente de venado, ${ }^{28}$ de casi un metro de largo que, unidos y doblados a manera de biombo, hacen un pequeño libro compacto, cuyos lados alcanzan poco menos de un palmo de la mano (de $15.5 \mathrm{~cm}$ de altura por $16.5 \mathrm{~cm}$ de largo). En total se compone de 46 láminas, 24 por el anverso y 22 por el reverso, dos de ellas son las cubiertas sin base de preparación, una de las cuales todavía conserva una mota de pelo.

Ahora se sabe más sobre sus materiales constitutivos gracias a los estudios de molab (Movil Laboratory of European Union) publicados recientemente, ${ }^{29}$ los cuales confirman que la base de preparación blanca-grisácea de la superficie está compuesta de yeso, además de anhidrita, otra forma cristalina de sulfato de calcio. Una interrogante no resuelta es qué aglutinante usaban para hacer una pasta no pulverulenta, lo que indica que además de yeso debió agregarse alguna otra sustancia para unirlo y hacerlo compacto. ${ }^{30}$

En los ańos sesenta del siglo pasado, cuando era posible la toma de muestras, se estudió el Códice Colombino y se encontró almidón, ${ }^{3 \mathrm{II}}$ mas no se ha identificado de dónde se obtuvo. En las fuentes se menciona el uso del tzauhtli, ${ }^{22}$ mucílago de orquídea como aglutinante, aunque también puede ser algún derivado del maíz u otro almidón. En tiempo reciente, bajo rayos uv, se encontraron en este mismo códice tres diferentes tipos de adhesivos, posiblemente

28. Recientemente Ludo Snijders ha propuesto que podía ser de jaguar, lo cual sería posible debido a que, al menos en el área maya, existen imágenes en cerámica pintada del Clásico que lo demuestran. Sin embargo, no estoy del todo convencida de que las imágenes presentadas por este autor sean definitorias, pues el patrón de las manchas reflejadas en las imágenes trabajadas por él no corresponde con el de la mota que aún pervive en el soporte.

29. En lo sucesivo los datos sobre los materiales mencionados provienen de Davide Domenici, Costanza Miliani y Antonio Sgamellotti, "Cultural and Historical Implications of Non-descructive Analyses on Mesoamerican Codices in the Bodleian Libraries", en Mexican Manuscripts. New Scientific Approaches and Interpretation, Maarten Jansen, Virginia Lladó-Buisán y Ludo Snijders, eds. (Leiden: Koninklijke Brill NV, 20I9), I6I.

30. Por contraste, en algunos códices coloniales la base de preparación se aprecia más pulverulenta, lo que podría ser indicio de la ausencia de aglutinante. Carolusa González, "Análisis de pigmentos en ocho códices mexicanos sobre piel”, tesis de maestría en Ciencias (Leicester, Inglaterra: Ciencias de la Conservación, 1998).

3I. Luis Torres, Antonio Sotomayor y Ticul Álvarez, "Análisis de los materiales del Códice Colombino", en Alfonso Caso, Interpretación del Códice Colombino (Ciudad de México: SMA, 1966), 92.

32. Francisco Hernández, "Historia de los minerales", en Antigüedades de la Nueva España. Obras completas (Ciudad de México: Universidad Nacional Autónoma de México, I959 [I570]), II7. 


\section{DOI: https://doi.org/10.22201/iie.18703062e.2021.118.2745}

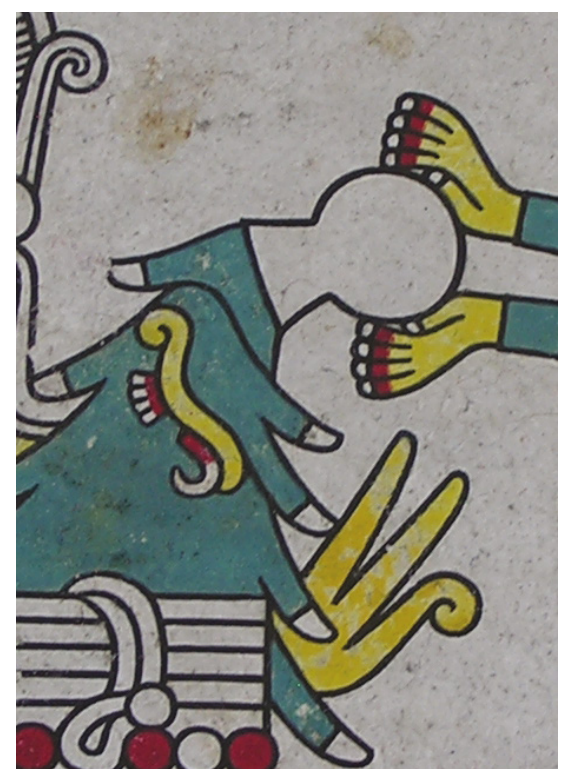

2. Lámina 46, detalle, Códice Laud, Biblioteca Bodleiana, Oxford, Reino Unido. Foto de la autora.

desde colas animales, gomas y resinas vegetales..$^{33}$ El tema del aglutinante sigue siendo un desafío para la investigación de los códices mesoamericanos, pues la teconología desarrollada para la identificación de materiales no ha podido diferenciar si la proteína que detectan los equipos procede del aglutinante de la base de preparación, de una cola animal de contenido proteínico o de la piel. ${ }^{34}$

Bajo el lente del microscopio óptico el Códice Laud revela sus secretos. La observación puntual me permitió apreciar que la base de preparación se aplicó en capas sucesivas y, a juzgar por el brillo que se observa con luz rasante, se bruñó, lo que creó una superficie tersa y homogénea, lista para que una mano muy experimentada pintara con soltura, sin tropiezos, y cuyo resultado fue una espléndida calidad de línea (fig. 2).

33. Sandra Zetina, José Luis Ruvalcaba, Tatiana Falcón, Jesús Arenas Alatorre, Saeko Yangisawa, Marisa Álvarez Icaza y Eumelia Hernández, "Material Study of the Codex Colombino", en Science and Art. The painted surface, Antonio Sgamellotti, Giovanni Brunetto Brunetti y Costanza Miliani, eds. (Londres y Cambridge: Royal Society of Chemistry, 2014 ), I27.

34. Chiara Grazia, David Buti, Laura Cartechini y Francesca Rosi, "Exploring the Materiality of Mesoamerican Manuscripts by Non-Invasive Spectroscopic Methods: Codex Laud, Bodley, Selden, Mendoza and Selden Roll at Bodleian Library", en Mexican Manuscripts. New Scientific Approaches and Interpretation, M. Jansen, V. Lladó-Buisán y L. Snijders, eds. (Leiden: Koninklijke Brill NV, 20I9), I4I. 
3. Lámina 29, detalle, Códice

Laud, Biblioteca Bodleiana, Oxford, Reino Unido. Foto de la

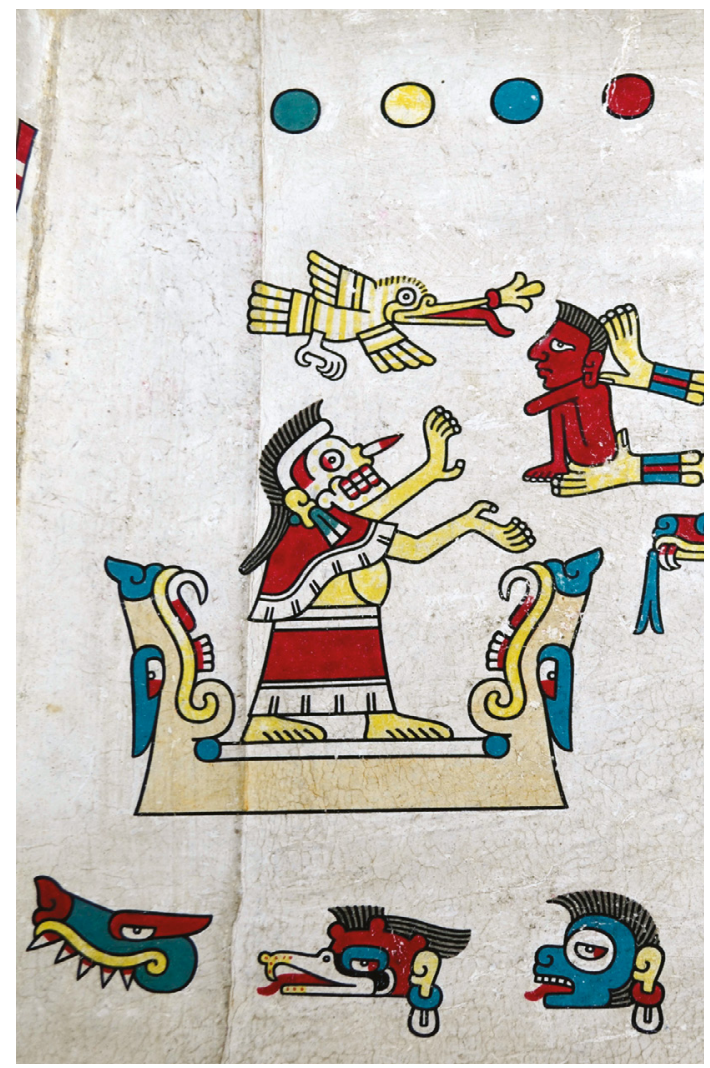
autora, 20I2.

El espacio pictórico se planeó con todo cuidado, de manera que por el anverso las uniones de los segmentos de piel son casi imperceptibles, fueron tapadas por la base de preparación y coinciden con la división de las láminas; por el reverso, las uniones están tan bien selladas que la capa pictórica aplicada encima de ellas todavía se mantiene muy bien conservada después de tantos siglos (fig. 3).

Mis inspecciones permiten señalar que, una vez preparada la superficie pictórica, se dividió el espacio por medio de gruesas líneas rojas, rectas y perpendiculares (figs. 5a y $5 \mathrm{~d}$ ), trazadas con un instrumento de apoyo, como una regla de madera que, junto con los círculos casi perfectos, reflejan el gusto de los artistas por la geometría, la simetría y el equilibrio. 


\section{DOI: https://doi.org/10.22201/iie.18703062e.2021.118.2745}

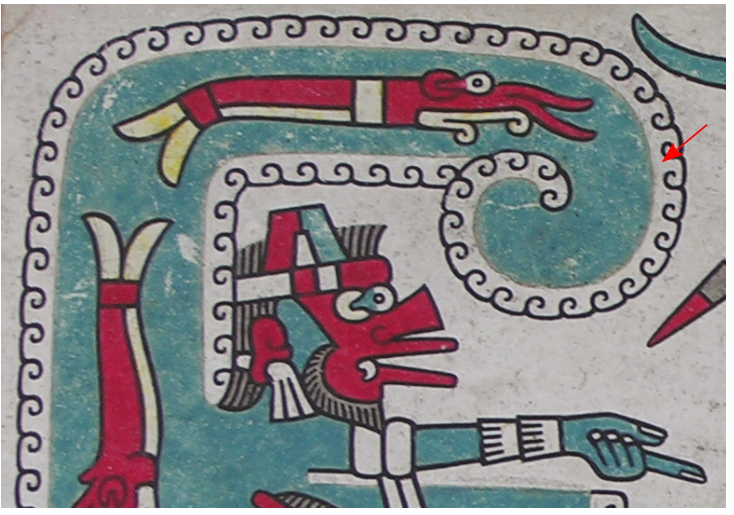

4. Lámina 39, detalle, Códice Laud, Biblioteca Bodleiana, Oxford, Reino Unido. Foto de la autora, 2009.

En cambio, las figuras se trazaron a pulso o con moldes individuales, pues no he detectado dos figuras idénticas; de hecho, sostengo que las pequeñas diferencias en la forma de los glifos de día, por ejemplo, marcan cambios en el significado. ${ }^{35}$ Como se puede apreciar en las imágenes, la precisión de la línea lograda por los artistas del Códice Laud es realmente impresionante; para lograr esto se debió haber hecho un boceto o dibujo preparatorio de las figuras, aunque es muy dificil de percibir porque por lo común la línea de tinta negra se trazó exactamente sobre él, ocultándolo; sin embargo, en un detalle de la lámina 39 sí se puede observar. El artista, con gran maestría y sutileza, no aplicó una línea de tinta negra de contorno para indicar la continuidad entre el agua y la espuma (fig. 4).

Sugiero que la línea negra de contorno se trazó con un instrumento que al hacer contacto con la superficie dejó una huella; si se observa con atención, se puede ver una línea blanca brillante diminuta que corre paralela en ambos lados de la línea de contorno. También es posible que antes del contorno de tinta, se hiciera una incisión y sobre ésta se aplicara la línea, pero las líneas brillantes que aparecen a sus lados son perfectamente paralelas al trazo de la línea de contorno (fig. 2), por lo que me inclino a proponer la primera explicación. Debido a que la línea es uniforme, sabemos que no se aplicó con un pincel, su trazo recuerda más bien a los estilógrafos modernos; debió haber

35. Por pequeños detalles se puede apreciar que los glifos de día siempre son diferentes; por ejemplo, el glifo de día Cocodrilo tiene cuatro o cinco dientes, las cejas y nariz también son distintas en la forma o color; esto indica un lugar preciso en el Tonalpohualli, de acuerdo con las comparaciones realizadas con el Borgia, el Vaticano B y el Cospi, donde se despliega completo. Álvarez Icaza, "El Códice Laud", 192 
a)

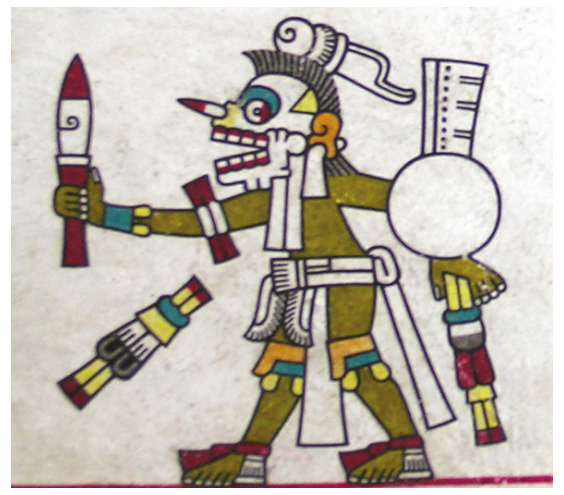

c)

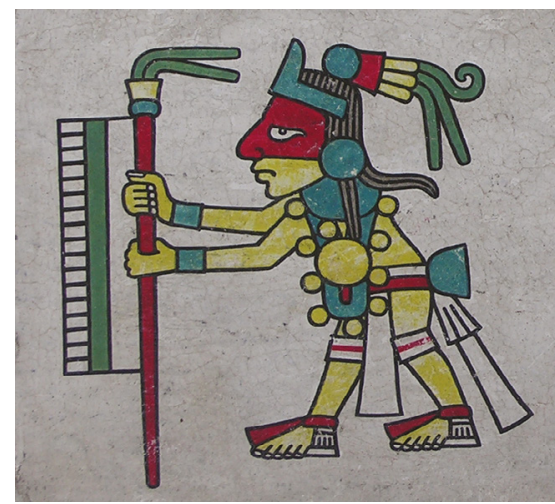

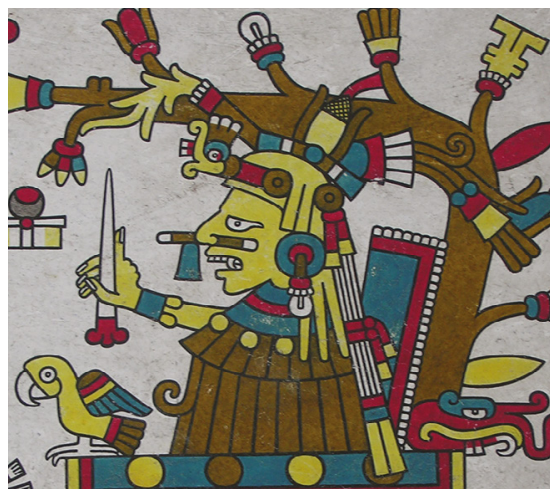

b)

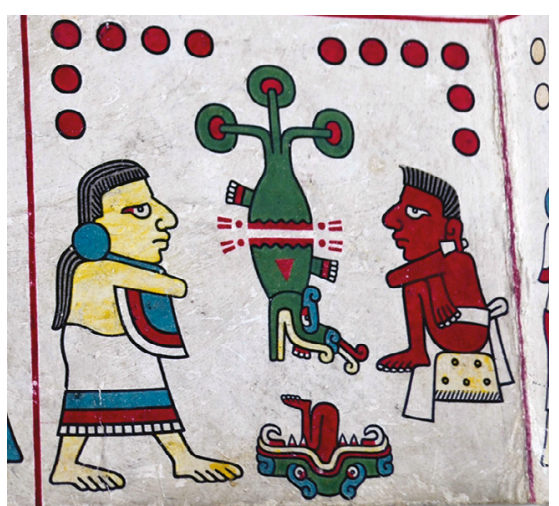

d)

5. a) Lámina I, detalle, capítulo I, Códice Laud, Biblioteca Bodleiana, Oxford, Reino Unido. Foto de la autora, 2009; b) lámina I5, detalle, capítulo 2, Códice Laud, Biblioteca Bodleiana, Oxford, Reino Unido. Foto de la autora, 2009; c) lámina 17, detalle, capítulo 3, Códice Laud, Biblioteca Bodleiana, Oxford, Reino Unido. Foto de la autora, 2009; d) lámina 34, detalle, capítulo 7, Códice Laud, Biblioteca Bodleiana, Oxford, Reino Unido. Foto de la autora, 2012.

sido un instrumento tubular de material perecedero, con un pivote en la punta que al presionarlo permitiera salir la tinta de forma regular y dejara huella de su trazo al contacto con la superficie.

Mi análisis visual de éste y otros códices me permite asentar que después de la línea de contorno se aplicaba el campo de color. Esto se puede apreciar en innumerables ejemplos en el Códice Laud, y es mucho más visible en las partes pequeñas donde la línea negra se opaca porque queda cubierta por la pintura, aplicada con pinceles (figs. 2 y 4). Este procedimiento, dibujo preparatorio-línea de contorno-color, se puede constatar en los códices, en la pintura mural 


\section{DOI: https://doi.org/10.22201/iie.18703062e.2021.118.2745}

198

MARÍA ISABEL ÁLVAREZ ICAZA LONGORIA

y en la cerámica polícroma, aunque en algunos casos puede haber repintes de la línea después del color.

\section{El color}

Otro de los aspectos más sorprendentes y llamativos del Códice Laud es su diversidad cromática y tonal, así como la deliberada elección de una gama específica de colores para cada capítulo, muy posiblemente, con un propósito relacionado con su significado; este tema lo sigo desarrollando, por las intrigantes razones que tuvieron los artistas al elegir una distinta tonalidad de colores para cada capítulo.

Desde el punto de vista de su apariencia, uno de los casos más claros del comportamiento del color en nuestro documento se puede observar en el uso del verde, como el que aparece en el capítulo i (Munsell $5 \mathrm{Y} 5 / 6$, fig. $5 \mathrm{a}$ ) y ligeramente más café en el 2 (M. $5 \mathrm{Y} 4 / 4$, fig. $5 \mathrm{~b}$ ); por razones aún desconocidas no vuelven a presentarse en el resto del códice. Según los estudios arqueométricos recientes, ${ }^{36}$ estos verdes no se derivan de un azul maya, sino de la mezcla de un colorante azul, amarillo y sepiolita.

Muy diferente es el que empieza a aparecer a partir del capítulo 3, de un tono "seco" (M. 7.5 G 6/6, fig. 5c), derivado de un azul o verde mayas; una variación diferente de este verde se puede ver en los capítulos 6 al II (fig. $5 \mathrm{~d}$ ).

De forma menos contundente de lo que ocurre con el color verde, pero igualmente interesante, son los cambios en la tonalidad en el azul que también corresponden con los de los capítulos. Por su apariencia y su materialidad sabemos que todos los azules son mayas, compuestos de índigo y paligorskita, con matices que van del turquesa al azul-verdoso más oscuro, o al grisáceo. En los capítulos I y 2 aparece un tono intenso de un azul más puro (entre Munsell 2.5 B $5 / 8$ y 2.5 B 6/8, figs. 6a y b). En el 3, aparece uno más claro (M. ıo GB 6/4, fig. 5 c). En el 4 hay una sutil combinación de un tono más azul y otro más verdoso (fig. 23); mientras que en el capítulo 6 hay un tono azul-verdoso intenso que sólo aparece en este capítulo (fig. 6c); y en el 7 aparece el tono más grisáceo de todo el códice (fig. 6d).

A diferencia de los colores anteriores, la variación en la tonalidad del amarillo puede explicarse por su poca adherencia, quizá por el uso de un mineral, el

36. Domenici, Miliani y Sgamellotti, "Cultural and Historical Implications", I6I. 
a)

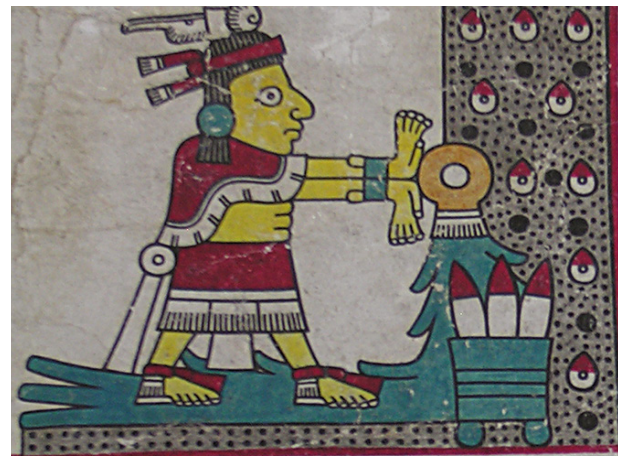



b) c)

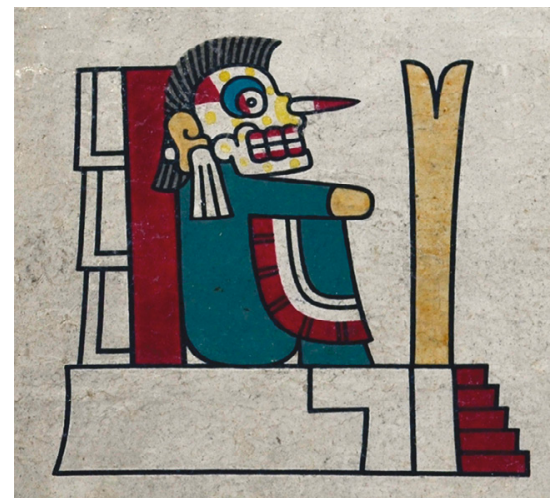

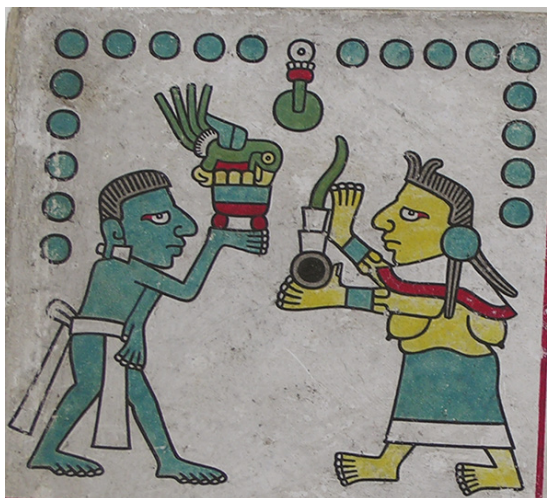

6. a) Lámina I, detalle, capítulo I, Códice Laud, Biblioteca Bodleiana, Oxford, Reino Unido. Foto de la autora, 2009; b) lámina 13, detalle, capítulo 2, Códice Laud, Biblioteca Bodleiana, Oxford, Reino Unido. Foto de la autora, 2009; c) lámina 32, detalle, capítulo 6, Códice Laud, Biblioteca Bodleiana, Oxford, Reino Unido. Foto de la autora, 20I2; d) lámina 36, detalle, capítulo 7, Códice Laud, Biblioteca Bodleiana, Oxford, Reino Unido. Foto de la autora, $20 \mathrm{I2}$.

oropimente, o de un aglutinante menos adherente. Los diversos tonos de beige y color "carne", así como la variedad de tonalidades del anaranjado, se identificaron como tintes orgánicos (figs. 3, 6a, с y I3a). ${ }^{37}$

En contraste, el rojo, el negro y el gris aparecen muy estables a lo largo de los capítulos. El rojo tiene un matiz sangre o vino, producto del uso de la cochinilla, muy probablemente mezclado con alumbre como mordiente. Mientras el

37. Domenici, Miliani y Sgamellotti, "Cultural and Historical Implications", I6I. 


\section{DOI: https://doi.org/10.22201/iie.18703062e.2021.118.2745}

rosa tiene una apariencia más transparente (fig. $6 \mathrm{~b}$ ); su tonalidad sugiere que es un color rojo con menor concentración de pigmento y más acuoso.

Desconozco aún las razones profundas y simbólicas de los cambios sutiles o más contundentes en el uso del color, pero es muy claro que esto no es accidental, o debido a que se hubiera acabado la pintura de determinado color. $\mathrm{El}$ analisis visual apunta hacia que el o los artistas efectuaron una deliberada elección de la gama cromática asociada a los capítulos temáticos específicos; es decir, los colores cambian de capítulo en capítulo de manera consistente y en cada uno permanecen sin variación de principio a fin.

En la medida en que la identificación de los materiales - y las técnicas precisas con que se elaboraron no sólo los códices sino otras obras de arte en las que se expresan las diversas escuelas pictóricas - se lleve a cabo, obtendremos mayor información sobre los artistas que crearon esta obra maestra de la cultura mesoamericana. Veamos ahora quiénes y dónde pudo haberse creado este sofisticado manuscrito pictográfico.

\section{La procedencia de los artistas}

Quizá uno de los mayores retos para desentrañar el tema de los creadores del Códice Laud es enfrentarse al hecho de que en varias zonas geográficas de Mesoamérica, desde siglos antes de la conquista española, se vivieron procesos de ocupación de un mismo territorio por diversos grupos a lo largo del tiempo, debido a movimientos migratorios y a expansiones políticas; ocupación que a veces fue simultánea, y otras, provocó el desplazamiento de pueblos. Por tanto, hablar de una región específica como posible lugar de origen del Códice Laud no lleva implícito, ni es obvio a qué grupo se está refiriendo particularmente.

En los estudios de los códices del Grupo Borgia es muy frecuente que se confunda la semejanza temática con el estilo y el lugar de procedencia, factor que en cierta medida determina que gran parte de lo escrito sobre el lugar de origen y el pueblo que pudo haber creado nuestro documento está íntimamente ligado a lo dicho para todo este grupo. Y si bien es cierto que comparten temas, como se dijo arriba — todos son Tonalamatl — no lo es así para el estilo ni para el lugar de origen.

A diferencia de los códices mixtecos, el Laud, así como los demás documentos que integran el Grupo Borgia, no proporciona datos históricos, genealógicos o topónimos, es decir, nombres de lugares, ni tampoco fechas absolutas 


\section{DOI: https://doi.org/10.22201/iie.18703062e.2021.118.2745}

LOS ARTISTAS DEL CÓDICE LAUD: EL ENIGMA DE SU ORIGEN

que brinden información sobre su procedencia. Además, el arte de pintar códices era anónimo y colectivo, los artistas no dejaron alguna firma, sello o marca de su nombre, aunque sí por medio de su estilo, su manera de representar y pensar el mundo. Analizaré a continuación las diferentes hipótesis propuestas con anterioridad sobre este tema.

\section{Un códice nábuatl}

El Códice Laud presenta dioses y símbolos característicos de la cultura náhuatl, como ya lo hicieron notar varios investigadores desde hace más de un siglo.. ${ }^{38}$ En lo que han diferido es en el lugar de origen que le atribuyen, pues lo que ha resultado más complejo de entender es en cuál de las diversas regiones con habitantes nahuas, para fines del Posclásico (I350-I52I d.C.), pudo haberse realizado este documento pictográfico.

\section{El valle de Puebla-Tlaxcala}

El valle de Puebla-Tlaxcala es una de las regiones con población náhuatl propuestas por Alfonso Caso hace casi un siglo como lugar de procedencia del Códice Borgia, e incluso de todos los miembros de este grupo, por su parecido con los murales de Tizatlán. ${ }^{39}$ Con el tiempo, se han ido reuniendo más argumentos y ejemplos de su sorprendente parecido con piezas o fragmentos de cerámica que nos permiten confirmar que el Códice Borgia procede de esta región. En esta misma línea, H. B. Nicholson ${ }^{40}$ demuestra que el complejo ico-

38. Del Paso y Troncoso, Descripción, historia y exposición, 58; Seler, Fejérváry-Mayer, 4-5; Martínez Marín, El Códice Laud; Śégota, "El olvido de una memoria”.

39. Las semejanzas encontradas son sobre todo iconográficas, pues compara la presencia de Tezcatlipoca en el Borgia y las pinturas de Tizatlán; y aunque al cambiar los soportes se observen cambios en la gama cromática, se confirma a Tezcatlipoca como una deidad suprema del valle de Puebla-Tlaxcala. Alfonso Caso, "Las ruinas de Tizatlán", Revista Mexicana de Estudios Históricos I, núm. 4 (julio-agosto de 1927): I45.

40. H.B. Nicholson, "The Eagle Claw/Tied Double Maize Ear Motif: the Cholula Polychrome Ceramic Tradition and Some Members of the Codex Borgia Group", en Nicholson y Quiñones eds., Mixteca-Puebla. Discoveries and Research in Mesoamerican Art and Archaeology (Culver City, Ca.: Labyrinthos, I994), pp. IOI-II6. 


\section{DOI: https://doi.org/10.22201/iie.18703062e.2021.118.2745}

nográfico de garra de águila, nudo de papel y doble espiga de maíz, de la cerámica polícroma Catalina o tipo Códice, tiene su mayor parecido con el Códice Borgia y con motivos que aparecen en el Cospi y el Vaticano $B$.

A su vez las excavaciones arqueológicas recientes apoyan estas propuestas. Patricia Plunket y Gabriela Uruñuela ${ }^{41}$ han encontrado en sus excavaciones de Cholula y alrededores, figuras peculiares de barro con agarradera y con la efigie de Tláloc en su cara frontal, muy semejantes a las que sostienen con la mano sacerdotes representantes de este dios en las láminas 27 y 28 del Códice Borgia. Elizabeth Boone,$^{42}$ por su lado, muestra notables semejanzas entre el altar polícromo de Ocotelulco y el Borgia. En la parte frontal del altar hay una escena donde un personaje con los atributos de Tezcatlipoca sale de un pedernal, que a su vez emerge de una vasija antropomorfa enmarcada por una serie de cuchillos de pedernal. Una escena semejante se puede apreciar en la lámina 32 de este códice, donde se representa el nacimiento de Quetzalcóatl y cinco Tezcatlipoca saliendo de un cuchillo antropomorfo, enmarcado igualmente por cuchillos de pedernal, tal cual se observan en el altar de Ocotelulco. Además de las semejanzas iconográficas señaladas, he encontrado sobre todo afinidades estilísticas, por ejemplo, en lo que respecta a las estrategias de representación para valores táctiles. Se pueden observar similitudes en la representación de textura en los cuerpos de agua entre un fragmento de cerámica de Ocotelulco y el Códice Borgia, donde se usan dos líneas negras ondulantes y una franja negra en medio de ellas (fig. 7a-b). En tiempo reciente, Ofelia Márquez ${ }^{43}$ señaló semejanzas muy claras entre la cerámica de Cholula y el Códice Borgia en numerosos fragmentos; aunque no comparto que un solo artista los haya pintado, sí apoyan la propuesta de que este códice se hizo en la ciudad de Cholula.

Estos estudios comparativos del arte de la región Puebla-Tlaxcala han aportado mayores evidencias no sólo para ubicar al Códice Borgia en esta región, sino que la persistencia de ciertas convenciones en diferentes soportes permiten entender que esta variedad estilística de la tradición Mixteca-Puebla; por lo que propongo que estamos ante la presencia de una escuela pictórica del Valle Puebla-Tlaxcala, con sede sobre todo en Cholula; aunque hay diferencias locales e históricas dentro del valle que deben estudiarse más.

4I. Gabriela Uruñuela, Patricia Plunket, Gilda Hernández y Juan Albaitero, "Biconical God Figurines from Cholula and the Codex Borgia”, Latin American Antiquity 8, núm. I (I996): 63-70.

42. Boone, Cycles of Times and Meaning, 222.

43. Ofelia Márquez, "El estilo de la cerámica polícroma de Cholula y el origen del Códice Borgia”, en Estilo y región en el arte mesoamericano, 207-219. 


\section{DOI: https://doi.org/10.22201/iie.18703062e.2021.118.2745}

a)

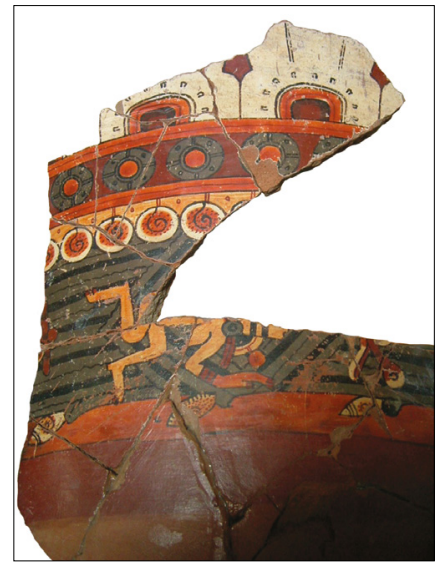

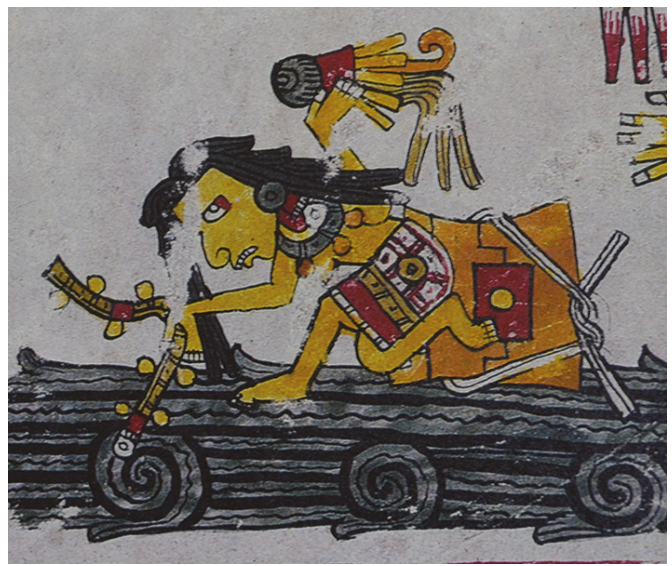

b) c)

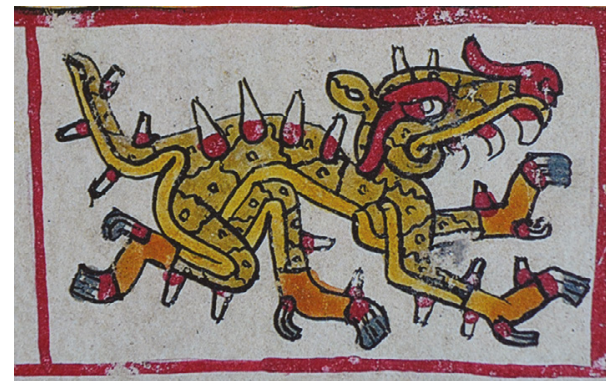

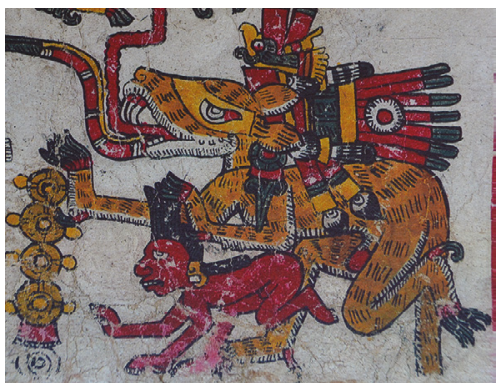

d)

7. a) Fragmento, vasija de Ocotelulco, Tlaxcala, Museo de Sitio de Ocotelulco, Tlaxcala. Foto de la autora, 2004. Secretaría de Cultura-INAH-MÉx. "Reproducción autorizada por el Instituto Nacional de Antropología e Historia”; b) lámina 65, detalle, Códice Borgia, reprografía; c) lámina 2I, detalle, Códice Borgia; d) lámina Io, detalle, Códice Borgia, reprografía.

No obstante las semejanzas temáticas y compositivas entre el Códice Borgia y el Laud, existen diferencias estilísticas muy importantes entre ellos como para pensar que éste proviene de la misma región. En el Borgia, los rasgos distintivos son una composición saturada de figuras en el espacio disponible que muestran un gusto por la ornamentación y la representación detallada de texturas, como en las escamas de cocodrilo (fig. 7c), ${ }^{44}$ el pelo animal (fig. 7 d) y los cuerpos de agua aludidos (fig. 7b). En el Laud, como se ha visto, es todo lo contrario; domina una economía y simplificación de formas, su composición

44. Todas las reprografías del Códice Borgia se tomaron de la edición facsimilar (Madrid: Biblioteca Apostólica Vaticana-Testimonio Compañía Editorial, 2008) 


\section{DOI: https://doi.org/10.22201/iie.18703062e.2021.118.2745}

204

MARÍA ISABEL ÁLVAREZ ICAZA LONGORIA

es equilibrada y las figuras se distinguen claramente unas de otras. Por ello, si el estilo del Laud es diferente al de la "escuela" del valle de Puebla-Tlaxcala, se puede inferir entonces que no proviene de esta región.

\section{La cuenca de México}

Ésta es otra región náhuatl propuesta desde el siglo xix por Francisco del Paso y Troncoso ${ }^{45}$ como lugar de origen de nuestro documento. Este caso es más complejo de analizar por las dificultades que presenta la definición del estilo mexica y la elección de un códice representativo con el cual comparar el Códice Laud, pues la mayoría de los especialistas coincide en que no existen códices mexicas incontrovertiblemente prehispánicos; ${ }^{46}$ lo que dicho sea de paso, no quiere decir que no existan códices nahuas de esta época. Los que más se acercan a los mexicas son los coloniales tempranos, con poca influencia de los cánones europeos. De éstos, los cosmológicos que se conocen son el códice Borbónico, el Tonalamatl de Aubin (tiras largas dobladas como biombo con papel amate), y la primera sección del Telleriano Remensis (con formato y papel europeo). Descarto este último por ser más tardío y al Tonalamatl de Aubin. ${ }^{47}$

En relación con la pintura mural mexica, los escasos fragmentos adosados o separados del muro que han aparecido en las excavaciones de las últimas décadas, desafortunadamente están muy deteriorados y sólo se tienen reproducciones de ellos; por ello decidí no incorporarlos en el corpus del estudio. Si bien es patente que algunos elementos como la composición, la proporción de la figura humana, algunas formas y convenciones pueden ser valorados con estos materiales, las sutilezas de las formas como la línea, el color, o la manera de dibujar los pies, los ojos, las manos y otros aspectos diagnósticos, no son apreciables en una reproducción, por lo que con dificultad pueden considerarse en un estudio comparativo sobre el estilo. Al considerar lo anterior, elegí comparar el estilo del Códice Laud con el del Códice Borbónico, pintado en las primeras décadas después de la Conquista pues, como lo han propuesto D. Robertson, ${ }^{48}$

45. Del Paso y Troncoso, Descripción, historia y exposición, 57.

46. Escalante, Los códices mesoamericanos, 62.

47. Aunque tuve acceso a las imágenes digitales no se me permitió el acceso al original, por lo que tuve que descartarlo del estudio. Sin embargo, desde mi punto de vista puede ser un códice mexica.

48. Robertson, Mexican Manuscript Painting, 91-93. 


\section{DOI: https://doi.org/10.22201/iie.18703062e.2021.118.2745}

LOS ARTISTAS DEL CÓDICE LAUD: EL ENIGMA DE SU ORIGEN

H. B. Nicholson ${ }^{49}$ y E. Boone, ${ }^{50}$ la primera sección del Códice Borbónico comparte elementos tradicionales con los relieves y con otras obras de indudable origen mexica.

Sin profundizar en la definición del estilo mexica, ni participar en las controversias que existen en torno a si es un arte naturalista ${ }^{\text {sI }} \mathrm{o}$ más bien esquemático, ${ }^{52}$ no me cabe duda de que es necesario hacer comparaciones específicas de la temporalidad de las pinturas para poder definir mejor los estilos, como ha señalado Leonardo López Luján..$^{33}$

Hechas estas aclaraciones y salvedades, retomo algunas de las cualidades señaladas por Elizabeth Boone ${ }^{54}$ que orientan el conocimiento y precisan la definición del estilo mexica ejemplificado en las representaciones del "monstruo de la tierra" o Tlaltecuhtli en la caja pintada de Tizapán, en el Códice Borbónico (fig. 8a), y los relieves plasmados en esculturas de esta misma deidad (fig. 8b). Comparten convenciones plásticas como la forma de representar los rizos de la cabellera.

En el Códice Borbónico ocurre algo parecido al Códice Borgia, en relación con la representación profusa de texturas, como en las plumas, la piel o el algodón (fig. 9). Como vimos, las formas en el Códice Laud son más esquemáticas, geométricas y rígidas (fig. 5b), mientras que las del Borbónico son más sueltas, curvas y naturalistas, con una prolija representación de textura; y la diferencia en el tratamiento del cabello, las plumas o los adornos de algodón es notable (figs. 9 y I3f).

49. Henry B. Nicholson, "The Mixteca-Puebla Concept in Mesoamerican Archaeology: A Re-Examination", en Alana Cordy-Collins y Jean Stern, eds., Pre-Columbian Art History. Selected Readings (Palo Alto, Ca.: Peek Publications, I977), iı6.

50. Elizabeth Boone, "Towards to More Precise Definition of the Aztec Painting Style", en Alana Cordy-Collins ed., Pre-Columbian Art History: Selected Readings (Palo Alto, Ca.: Peek Publications, 1982), 156.

5I. Nicholson, "The Mixteca-Puebla Concept", ir6; Boone, "Towards to More Precise Definition”, I56-158. Coincido con Leonardo López Luján en que la última etapa de la historia mexica es la de mayor refinamiento y cuando la escultura imperial tiende al naturalismo. Leonardo López Luján, La Casa de las Águilas. Un ejemplo de arquitectura religiosa de Tenochtitlan, t. I (Ciudad de México: Instituto Nacional de Antropología e Historia-Consejo Nacional para la Cultura y las Artes-Mesoamerican Archive and Research Project, Harvard University-CFE, 2006), 122.

52. Para una discusión sobre el "naturalismo" véase Pablo Escalante, Los códices mesoamericanos, 87-98; y Leonardo López Luján, La Casa de las Águilas, 122.

53. López Luján, La Casa de las Águilas, I22.

54. Boone, "Towards to More Precise Definition", i56. 
DOI: https://doi.org/10.22201/iie.18703062e.2021.118.2745

206

MARÍA ISABEL ÁLVAREZ ICAZA LONGORIA

a)

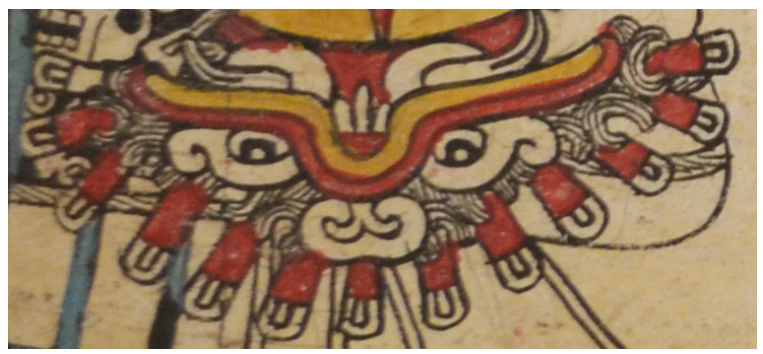

b)

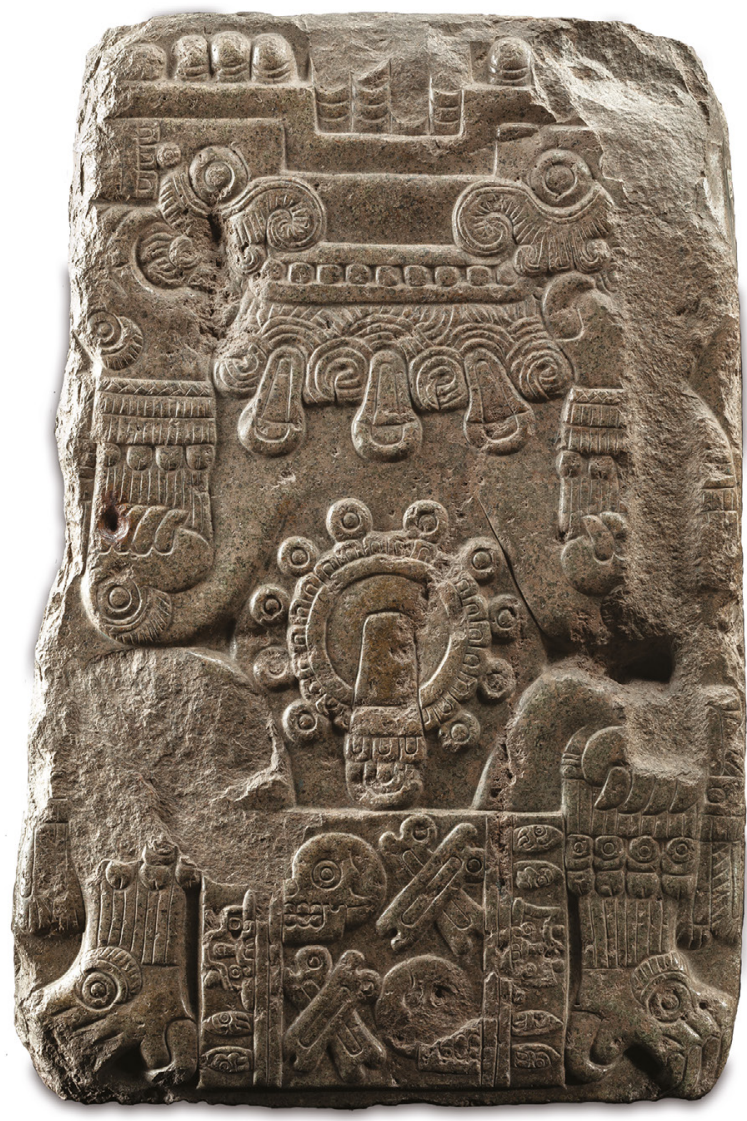

8. a) Lámina 9, detalle, Códice Borbónico, Biblioteca de la Asamblea Nacional, París, Francia. Foto de la autora, 2016; b) relieve de Tlaltecuhtli, Museo Nacional de Antropología. 
9. Lámina I2, detalle, Códice Borbónico, Biblioteca de la Asamblea Nacional, París, Francia. Foto de la autora, 2016.

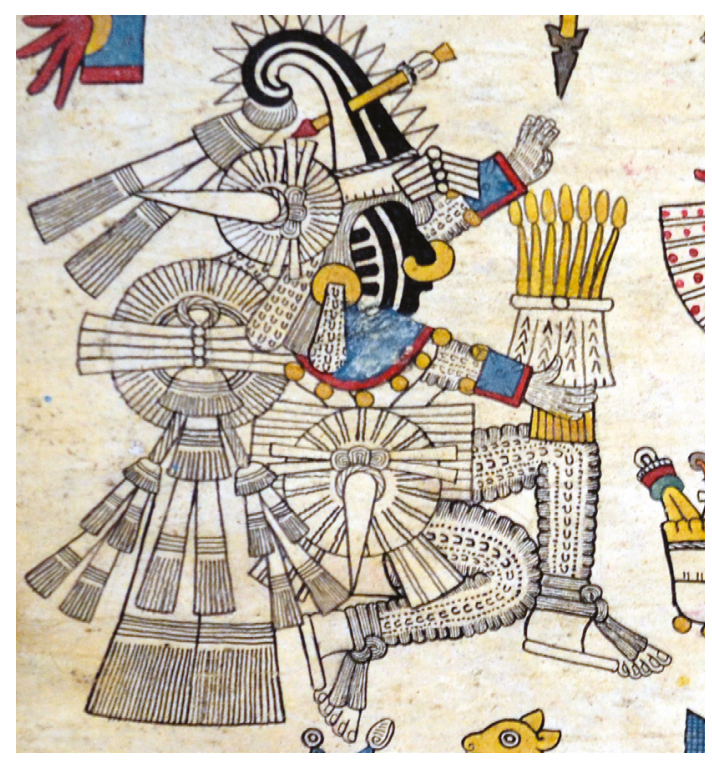

En algunos aspectos como en la descripción de valores táctiles para la representación de la piel y los adornos de papel del dios Iztlacoliuhqui (fig. 9), el Borbónico comparte elementos con los códices del valle de Puebla-Tlaxcala, aunque ostenta un estilo propiamente mexica; como se puede ver en las convenciones que se siguen para ilustrar ciertos glifos de día, Caña y Cocodrilo (figs. Ioa-Ioe), donde se distingue con claridad el estilo de este códice, el Telleriano Remensis (fig. Iob) y el Tonalamatl de Aubin, por un lado; y el de otros códices adivinatorios como el Borgia, Fejérváry, el Laud (figs. Ioc-Ioe) y los mixtecos, por el otro, como lo señalara Boone hace ya tiempo.s5

Así, aunque el Laud y el Borbónico son códices calendárico-adivinatorios, resultan muy diferentes en la forma, la representación de texturas y la línea. En nuestro objeto de estudio hay una simplificación de figuras, mientras que en el códice Borbónico es notoria la representación detallada de valores táctiles; diferencias estilísticas que me permiten descartar que el Laud fuese elaborado por los mexicas.

55. Boone, "Towards to More Precise Definition”, 156. 
DOI: https://doi.org/10.22201/iie.18703062e.2021.118.2745

208 MARÍA ISABEL ÁLVAREZ ICAZA LONGORIA

a)

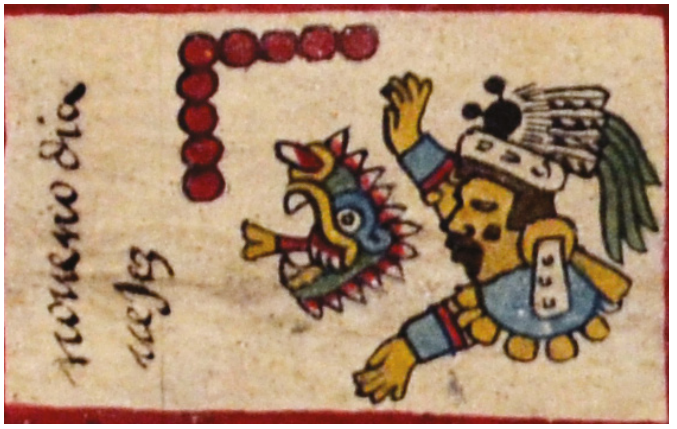

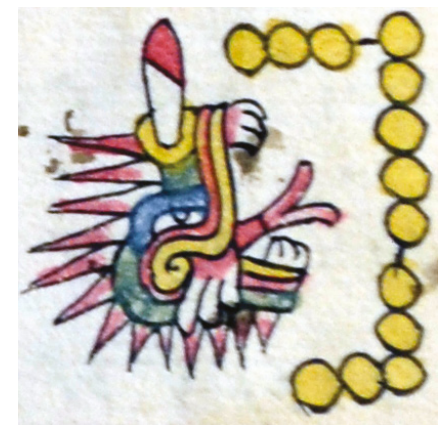

b)

c)
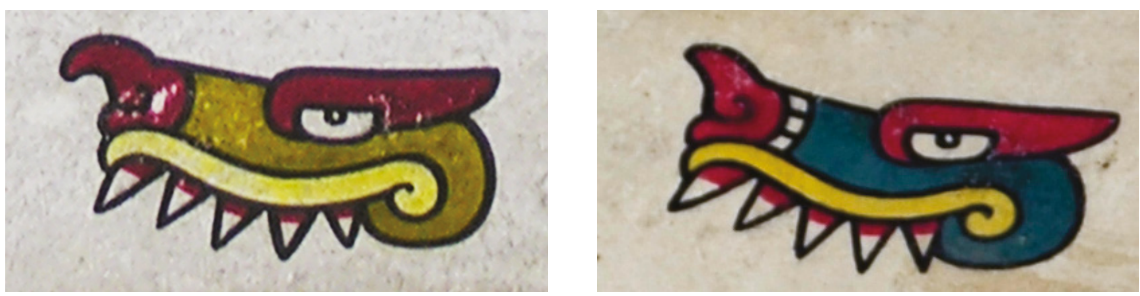

d)

e)

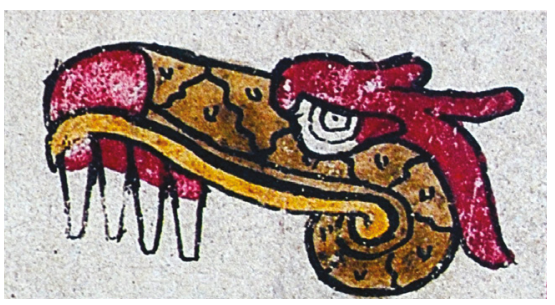

Io. a) Lámina 5, detalle, Códice Borbónico, Biblioteca de la Asamblea Nacional, París, Francia. Foto de la autora, 20I6; b) lámina 2Ir, detalle, Códice Telleriano-Remensis, Biblioteca Nacional de Francia, París, Francia. Foto de la autora, 2016; c) lámina 5, detalle, Códice Laud, Biblioteca Bodleiana, Oxford, Reino Unido. Foto de la autora, 2009; d) lámina I4, detalle, Códice

Fejérváry-Mayer, Museo del Mundo de Liverpool. Foto de la autora, 20I2; e) lámina 6, detalle, Códice Borgia.

\section{La Mixteca}

Para el caso de esta amplia región cultural que comprende parte de los actuales estados de Oaxaca, Guerrero y Puebla, contamos con códices históricos mixtecos que brindan información suficiente para fijar su zona de procedencia, lo cual facilita las comparaciones sobre bases firmes. Existe un acuerdo 


\section{DOI: https://doi.org/10.22201/iie.18703062e.2021.118.2745}

LOS ARTISTAS DEL CÓDICE LAUD: EL ENIGMA DE SU ORIGEN

generalizado entre los especialistas en que el Códice Nuttall y el Códice Vindobonensis son de la Mixteca Alta, y también es ampliamente reconocido que estos dos documentos conforman en realidad cuatro, ya que cada uno tiene un estilo diferente en sus lados. ${ }^{56}$

Desde el punto de vista estilístico, el Códice Laud y el Fejérváry-Mayer se asemejan más al reverso del Códice Nuttall y al anverso del Códice Vindobonensis que a los otros códices del Grupo Borgia. ${ }^{57}$ Estas similitudes se expresan por medio de sus aspectos plásticos, como lo son la calidad firme y precisa de la línea con trazos decididos. Si bien en el reverso del Códice Nuttall el dibujo preparatorio no coincide en muchas ocasiones con la línea de contorno (fig. II), debido quizá a la intervención de otro(s) artista(s), esta línea es casi tan precisa como la del Laud, incluso en los más pequeños detalles como en las uñas de las manos y los pies (fig. II). No sucede así con el anverso del Códice Vindobonensis, quizá porque el tamaño de las figuras humanas es demasiado pequeño o porque el artista no estaba interesado en estos detalles (fig. I2).$^{58}$ En ocasiones sólo se dibuja la uña del dedo gordo del pie y las uńas de la mano se representan dejando la punta de los dedos en blanco de forma rectangular.

Otras semejanzas entre el Laud y estos códices mixtecos son las convenciones usadas para representar valores táctiles, como el pelo animal (figs. I3a-d), la piel del cocodrilo (figs. I4a-d) y los cuerpos de agua (figs. I4a y b, I5a y b). Existe una preferencia por las formas planas, menos saturadas de líneas, en las que se prefiere la representación de textura en las siluetas de las figuras. En el pelo animal hay un extraordinario parecido entre el Laud, el Fejérváry-Mayer y los dos códices mixtecos referidos. En los cuerpos de agua, el dibujo también tiende a ser esquemático, no hay líneas ondulantes en el interior, como

56. Manuel A. Hermann Lejarazu, "Los códices de la Mixteca Alta. Historias de linajes y genealogías", Arqueología Mexicana. La Mixteca tres mil años de cultura en Oaxaca, Puebla y Guerrero XV, núm. 90 (2008): 48-52.

57. María Isabel Álvarez Icaza Longoria, "La definición estilística del Códice Laud. Una propuesta metodológica para análisis de estilo", tesis de licenciatura en Etnohistoria (Ciudad de México: Escuela Nacional de Antropología e Historia, 2006). Lo que impone revisar la inconsistente clasificación actual de los códices prehispánicos al agruparlos en: códices mayas, mixtecos y del Grupo Borgia, mezclando cualidades regionales y étnicas con temáticas.

58. Todas las reprografías del Códice Vindobonensis se tomaron de Códice Vindobonensis, comentarios de Jullie Leslie Furst, edición facsimilar (Nueva York: Universidad Estatal de Nueva York, 1978). 


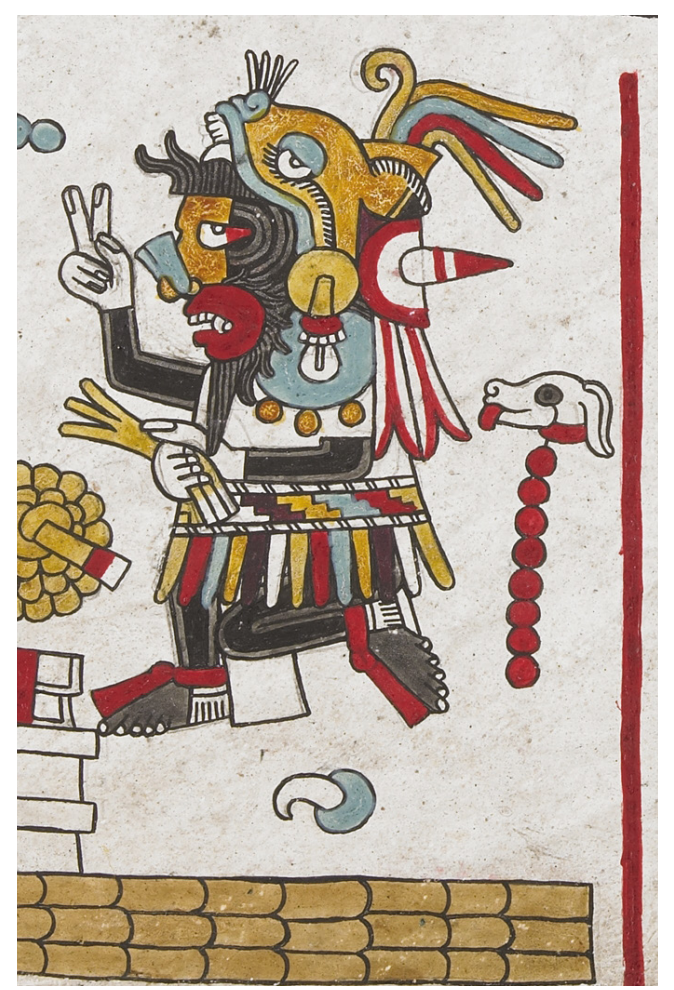

II. Lámina 72, reverso, detalle, Códice Nuttall. Museo Británico, Londres, Reino Unido.

en el Borgia (fig. 7b), sino volutas, caracoles o chalchihuites en la superficie (figs. I4a y b, I5a y b).

Las mayores semejanzas entre el reverso del Códice Nuttall y el Códice Laud las podemos ver en la forma de resolver las manos y los pies. Si observamos las figuras 5a-c y II, el parecido de las manos es muy notorio; comparten, como digo arriba, un gusto por la representación detallada de rasgos anatómicos, como el caso de las uñas vistas de perfil, que sólo se ven en estos documentos. Es importante enfatizar que en este aspecto el Nuttall y el Vindobonensis se distancian (figs. II y I2); en cambio son mayores las similitudes entre aquél y el Laud.

Sin embargo, algunas diferencias dan lugar a estimar que no pertenecen a la misma escuela; no tanto porque difieran en su temática y en la composición derivada de ella — en los mixtecos se usa una secuencia narrativa de sucesos, mientras que en los religiosos predominan los ciclos del tiempo y destino-, 
I2. Lámina 2, detalle, Códice Vindobonensis, reprografía.

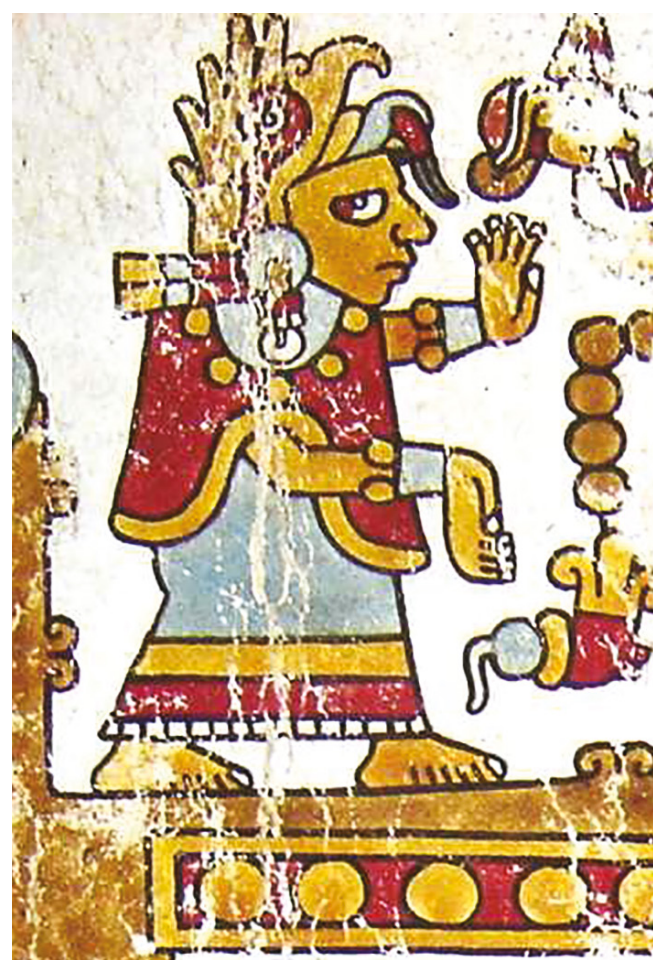

sino porque un acercamiento a su iconografía permite determinar que el Códice Laud expresa una cosmogonía náhuatl: no tiene glifos del año ni el nuuhu mixteco, y Quetzalcóatl se nombra Ce Ácatl y no Señor 9 Viento. El parecido estilístico del Laud con los códices mixtecos no define, por tanto, que este códice provenga de esta región.

¿Cómo explicar que estilísticamente son afines mientras que la iconografía en el Laud es náhuatl? ¿Qué puede significar esto? ¿Acaso las escuelas, la mixteca y la nahua, tuvieron estrecho contacto? ¿Responde a instrumentos, materiales y formación de artistas comunes? Las diferencias sugieren que los artistas de estos códices pertenecen a dos "talleres" o escuelas distintas, pero que se encuentran en estrecha relación. Y aunque es posible identificar una escuela por la dominancia de un estilo plasmado en diversos soportes, no debemos perder de vista la movilidad de las personas y de estos objetos. 
DOI: https://doi.org/10.22201/iie.18703062e.2021.118.2745

a)
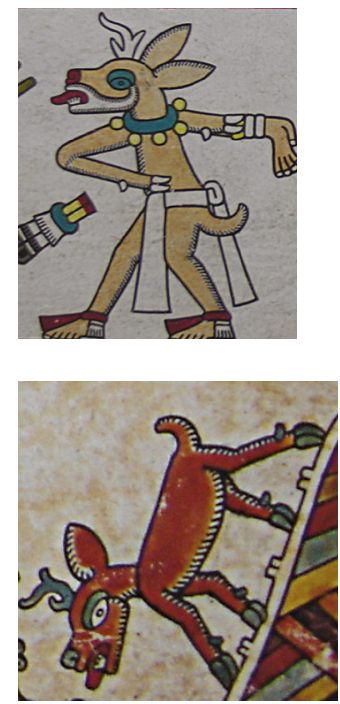

d) b)
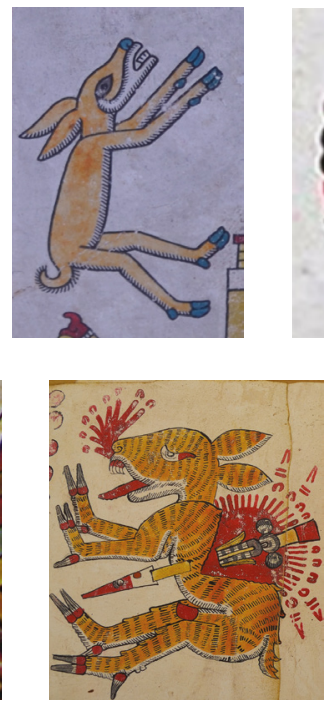

e)

c)
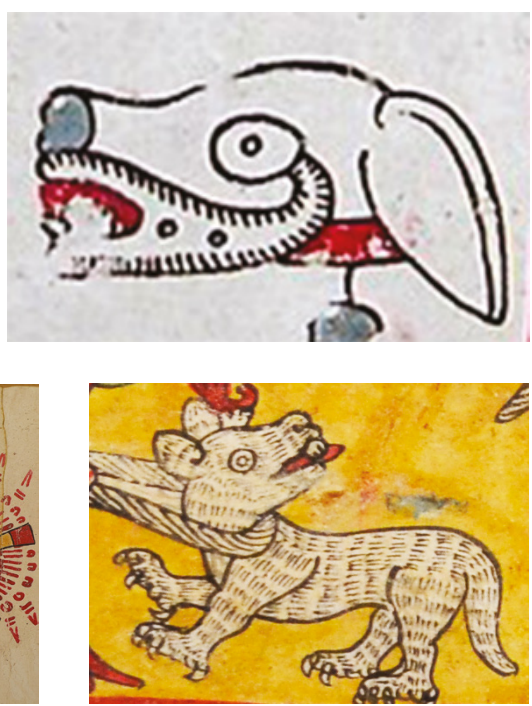

f)

13. a) Lámina 3, detalle, Códice Laud. Biblioteca Bodleiana, Oxford, Reino Unido. Foto de la autora, 2009; b) lámina 26, detalle, Códice Fejérváry. Museo del Mundo de Liverpool. Foto de la autora, 20I2; c) lámina 53, detalle, Códice Nuttall. Museo Británico, Londres, Reino Unido;

d) lámina 4I, detalle, Códice Vindobonensis; e) lámina 22, detalle, Códice Borgia; f) lámina 6, detalle, Códice Borbónico, Biblioteca de la Asamblea Nacional, París, Francia. Foto de la autora, 2016.

\section{La región cuicateca}

Los argumentos y las obras pictóricas elegidas para analizar la hipótesis de la procedencia de la región cuicateca, como han propuesto Anders y Jansen, se presentan en la última edición facsimilar del Códice Laud, en $1994 .{ }^{59}$ Los autores han sugerido que el Códice Laud pudo tener un origen cuicateco por el parecido que encuentran con la sección religiosa del Porfirio Díaz, cuyo origen está determinado en esta región. En particular, argumentan la semejanza iconográfica entre las láminas I(42) y 2(4I) del Porfirio Díaz y el capítulo 2 del Laud, de las láminas 9 a i6 (figs. I6a y b). Sin embargo, no es posible confirmar

59. Anders, Jansen y Cruz Ortiz, Códice Laud, 267. 
a)

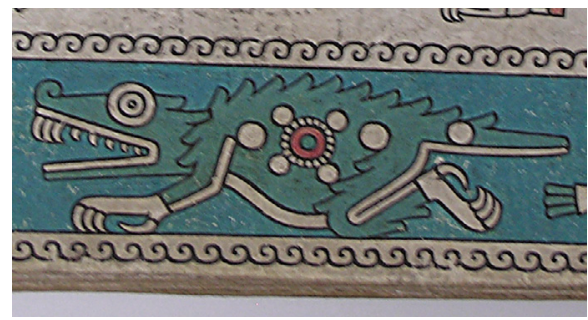

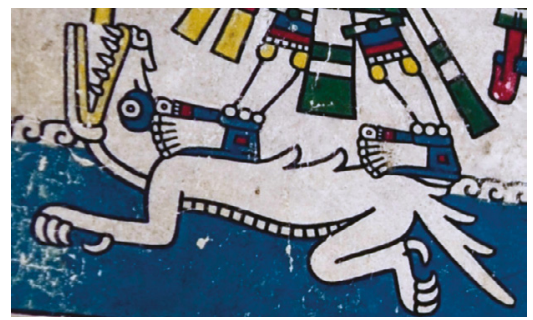

c)

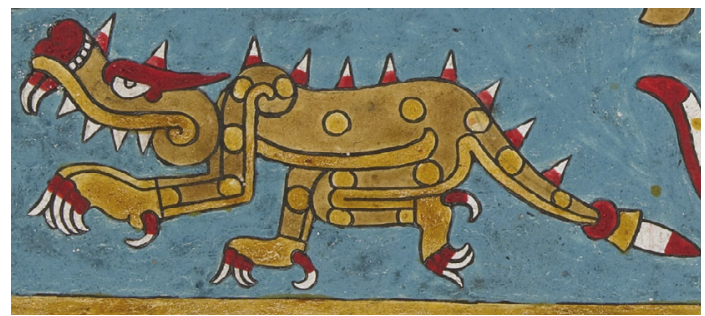

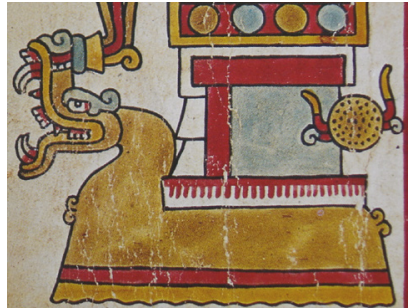

I4. a) Lámina 23, detalle, Códice Laud. Biblioteca Bodleiana, Oxford, Reino Unido. Foto de la autora, 20I2; b) lámina 4, detalle, Códice Fejérváry. Museo del Mundo de Liverpool, Reino Unido. Foto de la autora, 20I2; c) lámina 75, reverso, detalle, Códice Nuttall. Museo Británico, Londres, Reino Unido; d) lámina 8, reverso, detalle, Códice Vindobonensis.

la semejanza debido a que la primera lámina del Porfirio Díaz está perdida y en su estudio sólo se cuentan tres de los ocho dioses que conformarían un capítulo. Es importante resaltar, además, el carácter más sintético del Porfirio Díaz, donde el capítulo se conforma por dos láminas, mientras en el Laud son ocho.

Por otro lado, las semejanzas en la estructura calendárica en la versión abreviada del Tonalpohualli afilian más al códice Porfirio Díaz con el Códice Borgia (láminas 75-76) que con el Códice Laud: las trecenas se dividen en 6 y 7 en los dos primeros, mientras en el Laud, se dividen en 8 y 5 .

Por tanto, pienso que no tenemos muy fuertes argumentos para relacionar estos dos documentos desde el punto de vista de la iconografía. Sin embargo, si en este códice cuicateco se representan dioses de la religión náhuatl, o al menos son referidos por los investigadores en correspondencia con ella, ¿se trata de artistas cuicatecos aculturados por los nahuas? O bien, ¿se trata de una religión compartida por grupos con diferente lengua? ¿No es esto, acaso, lo que caracteriza a la tradición iconográfica y estilística Mixteca-Puebla? Es decir, un repertorio iconográfico que comparte una ideología. Pero ¿qué tan común es este repertorio?, y ¿qué tan diferente? ¿Este repertorio es exclusivo de los nahuas? o 
a)

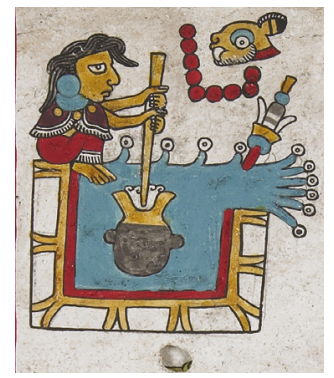

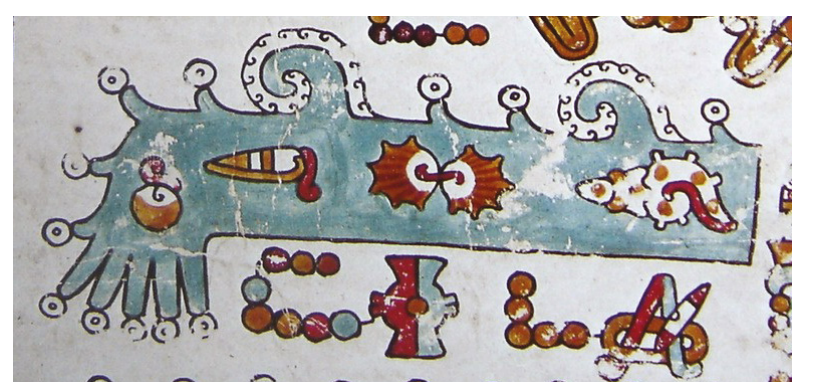

b)

I5. a) Lámina 74, detalle, Códice Nuttall. Museo Británico, Londres, Reino Unido; b) lámina 47, detalle, Códice Vindobonensis.

¿a cuál de ellos podría considerársele así y a cuál cuicateco o mixteco? ¿Es en su mayoría un repertorio compartido? ¿Podemos encontrar en este aspecto claves para la identificación de su procedencia?

$\mathrm{Al}$ intentar responder a estas preguntas se han hecho importantes aportaciones alrededor del repertorio iconográfico de la cerámica polícroma, como en los estudios de Michael Lind ${ }^{60}$ y Gilda Hernández; ${ }^{61}$ en el sentido de clasificar los símbolos utilizados, en el último caso, de acuerdo con complejos iconográficos; $y$, en el primero, para ubicar diferencias regionales. No obstante, hace falta ampliar estos estudios para entender cómo y en qué medida se relacionan las preferencias iconográficas entre los diferentes grupos que comparten esta tradición. Si profundizamos en esta línea de estudio, la distinción del repertorio iconográfico puede ser de mucha utilidad para encontrar pistas que permitan entender mejor si la preeminencia de ciertos símbolos sobre otros en los códices adivinatorios, y en otras obras de arte, son rasgos identitarios de un grupo político o cultural, y determinar la manera en la que se relacionan.

Pero más allá de entender estos asuntos, lo que es claro es que el estilo pictórico del Códice Porfirio Díaz es demasiado diferente al del Laud como para pensar que pertenecen a la misma zona de procedencia y, mucho menos, a la misma escuela pictórica. En la línea, la forma, la preparación de la superficie pictórica y, por supuesto, en el color, es donde se encuentran las mayores diferencias, dado que en el Porfirio Día sólo tenemos dibujos a tinta (fig. I6a). Así,

6o. Lind, "Cholulteca and Mixteca Polichromes", 79-99.

6I. Gilda Hernández Sánchez, Vasijas para ceremonia. Iconografía de la cerámica tipo Códice del Estilo Mixteca-Puebla (Leiden: CNWS Publications, 2005). 
a)

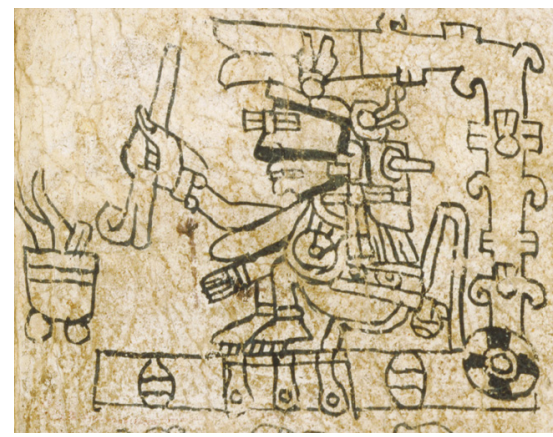

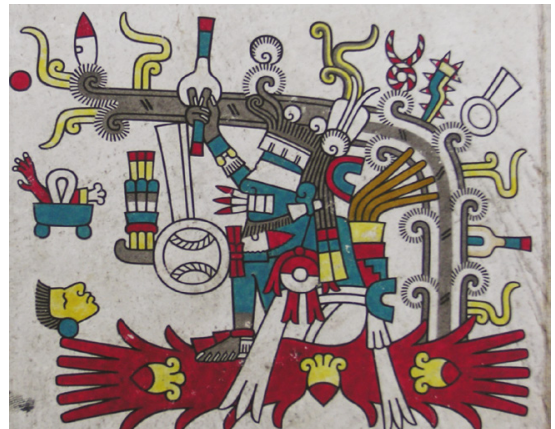

b)

I6. a) Lámina 42, detalle, Códice Porfirio Díaz, tomada de Códices Cuicatecos: Porfirio Díazy Fernández Leal, Sebastián van Doesburg, coord. (México: M. A. Porrúa-Gobierno del Estado de Oaxaca, 200I); b) lámina I2, detalle, Códice Laud. Biblioteca Bodleiana, Oxford, Reino Unido. Foto de la autora, 2009.

por el aspecto iconográfico y el estilístico, descartaría también la región cuicateca como posible lugar de origen del documento que nos ocupa.

\section{La costa del Golfo}

Ésta es otra región que ha sido también sugerida con cierta fuerza como lugar de origen del Códice Laud y del Fejérváry-Mayer. La primera dificultad para corroborar esta propuesta estriba en que la llanura costera del Golfo es una extensa zona geográfica, donde confluyen varias culturas por el intercambio marítimo y terrestre de productos e ideas; la costa, además, es un punto intermedio entre las tierras mayas y el Altiplano, y ha sido una fuente de abastecimiento de productos marítimos y ruta para la adquisición de bienes de prestigio de origen selvático.

H. B. Nicholson ${ }^{62}$ fue uno de los primeros en señalar semejanzas iconográficas del Códice Laud con la plástica de la costa del Golfo, por la reiterada aparición de Tlazoltéotl; la representación de mujeres con el pecho desnudo; la aparición de hachas y brazaletes; así como por la presencia del ave tlauhquechol, del papagayo, la tortuga, caracoles y la representación del mar.

62. Nicholson, "The Problem of the Provenience", I55. 


\section{DOI: https://doi.org/10.22201/iie.18703062e.2021.118.2745}

En cuanto a Tlazoltéotl, este investigador alude al origen huaxteco de esta diosa. ${ }^{63}$ Lo que hace particular su aparición en el Códice Laud, como ya se mencionó, es que en ningún otro códice esta deidad es patrona del Tonalpohualli. Así, la fuerte presencia de esta diosa vincula a nuestro códice con el Golfo, y también, directa o indirectamente, con los toltecas, pues varios autores afirman que esta deidad se incorporó al panteón náhuatl por medio de ellos. ${ }^{64}$ De modo que, si los dioses representados en el panteón del Laud corresponden con la religión náhuatl, entonces la presencia de esta diosa en el códice parece mostrar una mayor vinculación con los nahuas toltecas.

Estudios arqueológicos de la Mixtequilla, en la cuenca del río Papaloapan, indican la presencia de grupos nahuas, tanto desde el Posclásico Medio como en el Tardío. ${ }^{65}$ El arqueólogo Philip Drucker ${ }^{66}$ observó semejanzas entre la cerámica polícroma de esta región, específicamente del Cerro de las Mesas, con la de Cholula ${ }^{67}$ Los tipos cerámicos en los que encuentra parecido los llama Dull Buff Polichrome, que equivaldría a la Polícroma Mate de Noguera, y la Complicated Polychrome en la que encuentra semejanzas con la Polícroma Firme (Albina de Lind) y la Polícroma Laca (Catalina de Lind). ${ }^{68}$

Esta información la han ido confirmando y detallando más recientemente Barbara Starck, en sus propias excavaciones en la Mixtequilla, ${ }^{69}$ y Annick Daneels, ${ }^{70}$ en la cuenca baja y media del río Cotaxtla, donde han encontrado

63. Debe señalarse, sin embargo, que Tlazoltéotl era una diosa también adorada por varios grupos más al sur de la Huaxteca y anterior a ellos, a juzgar por la gran cantidad de esculturas de barro con representaciones de esta deidad procedentes del centro de Veracruz del periodo Clásico.

64. Martínez Marín, El Códice Laud, 8; Herman Beyer, "Conchas ornamentadas de la Huasteca. México”, en El México Antiguo, t. XI (Ciudad de México: Instituto Cultural Mexicano Alemán, 1969), 492; Nicholson, "The Problem of the Provenience”, I68.

65. Annick Daneels, "El patrón de asentamiento del periodo Clásico en la cuenca baja del río Cotaxtla, Centro de Veracruz", tesis de doctorado en Antropología (Universidad Nacional Autónoma de México, 2002), 339.

66. Philip Drucker, Ceramic Stratigraphy at Cerro de las Mesas, Veracruz, Mexico, Bureau of American Ethnology, Boletín I4 (Washington: Smithsonian Institution, I943), 48 y 49.

67. Nicholson, "The Problem of the Provenience", I55; Patricia Anawalt, "Costume Analysis and the Provenience of the Borgia Group Codices", American Antiquity 46, núm. 4 (I98I): 849.

68. Lind, "Cholulteca and Mixteca Polichromes", 8I.

69. Barbara Starck, "Gulf Lowland Ceramic Styles and Political Geography in Ancient Veracruz", en Olmecs to Aztec. Settlement Patterns in the Ancient Gulf Lowlands, Barbara Starck y Philip J. Arnold, eds. (Tucson: The University of Arizona Press, 1997), 306-307.

70. Daneels, "El patrón de asentamiento del periodo Clásico en la cuenca baja del río Cotaxtla", 339. "Settlement History in the Lower Cotaxtla Basin", en Olmecs to Aztec. Settlement 


\section{DOI: https://doi.org/10.22201/iie.18703062e.2021.118.2745}

LOS ARTISTAS DEL CÓDICE LAUD: EL ENIGMA DE SU ORIGEN

17. Apaxtle, Museo Regional de Palmillas, Veracruz. Foto de la autora, 2013 .

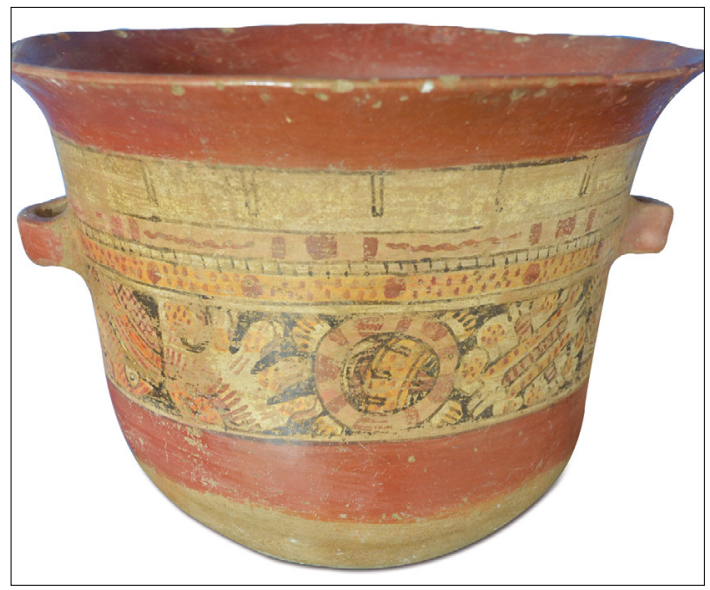

cerámica Polícroma Firme y Polícroma Laca. En su extensa investigación de campo en la zona, ${ }^{71}$ Daneels nota que esta cerámica no es de importación, sino de manufactura local, y empieza a aparecer en el Posclásico Medio y Tardío. ${ }^{72}$ Así, estas arqueólogas están de acuerdo en señalar que la cerámica polícroma encontrada en el centro-sur de Veracruz está vinculada a la cerámica Mixteca-Puebla de Cholula.

En efecto, el estilo pictórico y el repertorio iconográfico de ambas vasijas es muy semejante. Por ejemplo, un apaxtle del Museo Regional de Palmillas, Veracruz (fig. 17), presenta algunas similitudes con la cerámica Polícroma Firme de Cholula que Lind llama Albina (fig. I8), no sólo en la técnica de pintura precocción, su apariencia brillante, el predominio del fondo crema del engobe y la gama cromática sino, sobre todo, en el repertorio iconográfico sacrificial, el cual propongo que pertenece a los grupos nahuas tolteca-chichimeca del altiplano; ya que tiene sus antecedentes en Tula, como se puede ver en los frisos de la Pirámide $\mathrm{B}$, en los cráneos, huesos cruzados y corazones. Esta ideología relacionada con el sacrificio la imponen los toltecas cuando llegan a Cholula, como se expresa en este repertorio en la cerámica

Patterns in the Ancient Gulf Lowlands, Barbara Starck y Philip J. Arnold, eds. (Tucson: The University of Arizona Press, 1997).

7I. La arqueóloga considera en su estudio 242 sitios tan sólo en la cuenca baja del río Cotaxtla.

72. Daneels, "El patrón de asentamiento", 340 y 345. 


\section{DOI: https://doi.org/10.22201/iie.18703062e.2021.118.2745}

Albina del Posclásico Medio (II5O-I350 d.C.), ${ }^{73}$ manos cercenadas, huesos cruzados, corazones, pedernales y otros símbolos sacrificiales, que se ven también en el Golfo, como se muestra en el ejemplo (fig. 17). Este repertorio también es retomado por los mexicas, lo que se puede constatar en el discurso de legitimación política fincado en su herencia tolteca en la Piedra del Arzobispado, cuyo friso tiene todos estos símbolos, además de personajes con pectoral de mariposa a la manera de los guerreros de Tula.

Así, la afinidad iconográfica y estilística entre la cerámica de Cholula y esta región del Golfo implica descartar la zona costera como la región de origen del Códice Laud; como vimos, el estilo pictórico del valle de Puebla-Tlaxcala es diferente al de este códice. Sin embargo, la elección de Tláloc como patrono de los días, la aludida aparición de Tlazoltéotl como señora del Tonalpohualli y la forma de representación de las volutas para el humo, el vapor, o las nubes en el Laud, en un estilo muy cercano a lo que se observa en el arte del Golfo, hacen pensar en artistas nahuas ligados a esta zona.

Un aspecto que falta conocer es el estrecho vínculo que pareció existir entre el valle de Tehuacán, la región de Córdoba y la cuenca baja del Cotaxtla. Merecerían indagarse más los nexos por el abastecimiento común de la obsidiana del Pico de Orizaba (después del año Iooo d.C.), la tutoría del control de estas minas $^{74}$ y la existencia de cerámica con fondo sellado en ambas regiones.

Algunos estudiosos han destacado otros vínculos con el área maya, entre el Fejérváry-Mayer y el Laud, vía esta región del Golfo. Eduard Seler ha referido de manera específica el parecido entre el dios narigudo del códice FejérváryMayer (lám. 36) y el dios de los mercaderes y de los cultivadores de cacao de los mayas, ${ }^{75}$ Eek' Chuwah (ek-negro) o Ik' Chuwah entre los chontales de Acalan, actualmente Campeche. Lo que ha hecho suponer que los creadores de estos documentos pertenecían a un grupo que debía tener relaciones comerciales con el área maya, muy posiblemente con la costa de Tabasco y Campeche. Al seguir esta línea de pensamiento otros investigadores han profundizado sobre este tema, como Miguel León-Portilla, que propone que el Fejérváry es

73. Según la cronología de Lind, "Cholulteca and Mixteca Polichromes", 8I.

74. Annick Daneels y Fernando Miranda, "La industria prehispánica de la obsidiana en la región de Orizaba", en El valle de Orizaba. Textos de Historia y Antropología, Carlos Serrano y Agustín García Márquez, eds. (Ciudad de México: Universidad Nacional Autónoma de México/Museo de Antropología de la Universidad Veracruzana/ H. Ayuntamiento de Orizaba, 1999), 47.

75. Seler, Fejérváry-Mayer, 4-5. 
I8. Copa bicónica de Cholula, Museo Nacional de Antropología, Ciudad de México (bodega del Museo Nacional de Antropología, núm. de inv. IO-OIO932). Foto: MIAIL, 20I3. Secretaría de CulturaINAH-MÉx. "Reproducción autorizada por el Instituto Nacional de Antropología e Historia”.

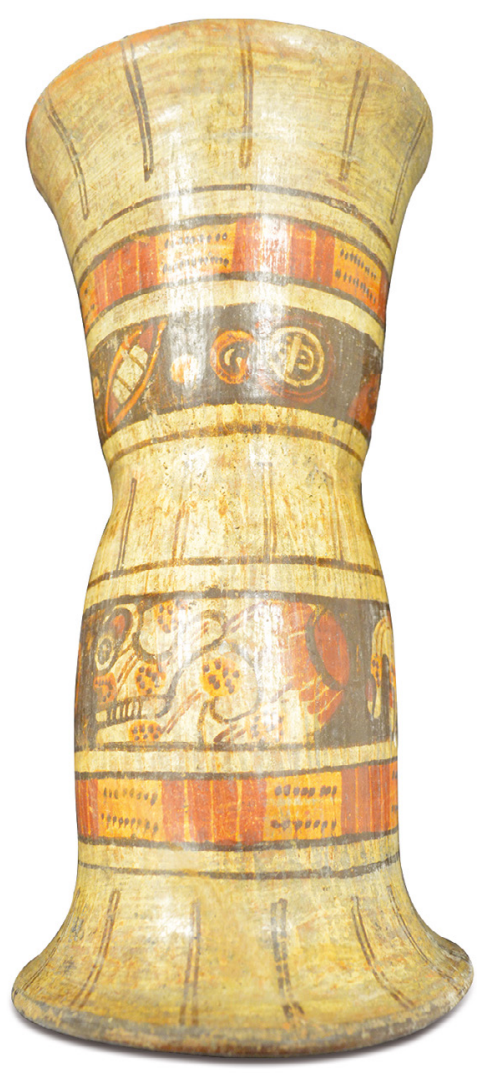

un Tonalamatl usado por pochtecas de Tlatelolco. Sin embargo, debe aclararse que en el Laud sólo un capítulo contiene el tema de los mercaderes y sus augurios, y no aparece el dios narigudo.

\section{El valle de Tehuacán}

Por último, una antigua y sugerente propuesta hecha por Eduard Seler ${ }^{76}$ hace más de un siglo, sobre la procedencia del Códice Laud y del Fejérváry-Mayer apunta hacia el valle de Tehuacán. Esta región conjuga las condiciones

76. Seler, Fejérváry-Mayer, 4-5. 


\section{DOI: https://doi.org/10.22201/iie.18703062e.2021.118.2745}

necesarias para ser el lugar de origen del Códice Laud: el valle fue habitado por población náhuatl, está vinculado a la costa del Golfo, y es cercano a la Mixteca Alta, lo que explica el parecido estilístico con códices de esta cultura.

El valle de Tehuacán es de suma importancia geográfica por ser un corredor que comunica al valle de Puebla-Tlaxcala con la costa del Golfo por el sur, a través del cañón de Tecomayauaca, hacia Tuxtepec y la Mixtequilla. Por vía fluvial el río Salado, que pasa por Tehuacán y nace en la región montañosa del noroeste, se junta con el Santo Domingo que a su vez desemboca en el río Papaloapan; el valle de Tehuacán tiene una fuerte conexión con Tuxtepec y con la cuenca de este río, tierras fértiles cercanas a los recursos marítimos del Golfo. Al sureste, este valle colinda con la zona mazateca y la cuicateca. Al poniente, un estrecho corredor lo comunica con la Mixteca Baja, a la cuenca del Atoyac, y más al suroeste con la Mixteca Alta y los Valles Centrales de Oaxaca (fig. I). La región ha sido ocupada desde tiempos muy antiguos por gente de la familia lingüística otomangue, chocho-popolocas, y más tarde por nahuas migrantes - tolteca nonoalcas - que llegaron después de la caída de Tula. ${ }^{77}$ Antes de su llegada, entre el 700-II5O d.C., estaba dominada por un gran centro ceremonial fortificado, localizado arriba de la actual comunidad popoloca de San Gabriel Chilac. Después de iIso d.C. este valle se caracterizó por una repentina explosión de población y emergieron tres nuevas ciudades-estado: Tehuacán, Cozcatlán y Teotitlán; las cuales fueron establecidas por gente de habla náhuatl, mientras que la región circundante era popoloca y mazateca. $7^{8}$

De acuerdo con el examen de los patrones de asentamiento del valle de Tehuacán, Pohl y Byland afirman que una población llegó procedente de Tula a fundar esas ciudades. Tanto los datos arqueológicos como etnohistóricos indican que después del colapso de Tula, entre el Iıoo y el ı200 d.C., una población significativa de toltecas migró hacia el sur de Puebla y norte de Oaxaca. ${ }^{79}$ Los popolocas fueron en parte desplazados, como se puede interpretar de lo dicho por Peter Gerhard; tanto en Tehuacán como en Cozcatlán la población para el siglo XVI era mayoritariamente nahua, con un porcentaje menor de

77. Anales de Cuauhtitlán o Códice Chimalpopoca. Leyenda de los soles, trad. del náhuatl, Feliciano Velázquez (Ciudad de México: Universidad Nacional Autónoma de México, 1975), I4-15.

78. John M. D. Pohl y Bruce Byland, "The Mixteca-Puebla Style and Early Socio-Political Interaction”, en Nicholson y Quiñones, eds., Mixteca-Puebla Discoveries and Research in Mesoamerican Art and Archaeology, 194.

79. Pohl y Byland, "The Mixteca-Puebla Style and Early Socio-Political Interaction”, I94. 


\section{DOI: https://doi.org/10.22201/iie.18703062e.2021.118.2745}

popolocas.$^{80}$ Es muy posible, entonces, que en Tehuacán convivieran de manera simultánea estos dos grupos durante el Posclásico Medio y Tardío (II5O-I52I d.C.), y que la élite de Xelhuan, su líder, se aliara con la élite popoloca local, como hicieron los toltecas en otras regiones.

Es importante recalcar que Tehuacán estaba inscrito en el sistema de alianzas entre élites, en donde los toltecas tuvieron un papel de primera importancia en la creación de estas redes que se tejieron con mixtecos, popolocas y chochos. Los cacicazgos de Tehuacán, Cozcatlán y Teotitlán estaban unidos por alianzas matrimoniales, como los toltecas hicieron en general para expandir su dominio. Lo hicieron con cholultecas (de posible filiación otomanguiana), huaxtecos, chichimecas, chochos de Coixtlahuaca y, al parecer, con los popolocas de Tehuacán ${ }^{8 \mathrm{r}}$ entre las alianzas más importantes. Su poderío se extendió además hacia el Golfo, como lo manifiesta el repertorio de su cerámica polícroma, como vimos arriba, pues era una ruta que se tomaba para ir a Tabasco y Campeche, puerta de entrada hacia las tierras mayas y hacia la península de Yucatán.

La confluencia de diferentes grupos en el valle de Tehuacán se aprecia de alguna manera en el arte, en la arquitectura, la cerámica y la pintura mural, y en ellos se ve un carácter claramente local que difiere de otras zonas vecinas. En la arquitectura urbana existen semejanzas entre la plaza principal de Tehuacán y la traza de la plaza central del Edificio B de Tula, flanqueada por pórticos; en el caso de Tula, enfrente y al lado, en el de Tehuacán en ambos lados.

Un aspecto importante a considerar es que no existe producción local de cerámica polícroma precocción como la de Cholula; la que se ha encontrado es de importación. ${ }^{82}$ Lo que ha sobrevivido de policromía en Tehuacán está presente en la escultura en barro y pintura mural con las que comparé al Códice Laud.

Respecto a la primera, son famosas unas esculturas pintadas después de la cocción, con o sin baño de engobe o estuco, conocidas con el nombre de "xantiles”. ${ }^{83}$ Aparecen en toda la región, desde Tehuacán hasta Teotitlán, y se

80. Peter Gerhard, Geografía histórica de la Nueva España I5I9-I82I (México: Universidad Nacional Autónoma de México, 1986), 268.

8I. Mary Elizabeth Smith y Ross Parmenter, The Codex Tulane, Middle American Research Institute, 6I (Nueva Orleans: Tulane University, 199I), II, 54 y 56.

82. Noemí Castillo Tejero, "Las cerámicas prehispánicas en la región Puebla-Tlaxcala durante el Posclásico", en La producción alfarera en el México Antiguo V, Leonor Merino y Ángel García Cook, coords. (Ciudad de México: Instituto Nacional de Antropología e Historia, 2007), I46. Excelentes ejemplares de esta cerámica se pueden apreciar en el museo de sitio de Tehuacán.

83. Según Eduardo Noguera este nombre viene de Santo, xanto, xantil. 


\section{DOI: https://doi.org/10.22201/iie.18703062e.2021.118.2745}

reconocen como una producción local importante de origen popoloca. ${ }^{84}$ Estos "xantiles" tienen representaciones de deidades, como Xochipilli, ${ }^{85}$ Tláloc, y personajes con los brazos apoyados en las rodillas. Algunas de estas esculturas son muy similares, pero no iguales, a unas que se encuentran en el centro-sur del Golfo. Las de Tehuacán tienen un estilo muy particular; la representación de la figura humana es un tanto abstracta, porque son esculturas formadas por cilindros huecos en el tronco y extremidades, mientras que la cabeza por lo común es sólida y, a diferencia del cuerpo, más detallada en el rostro y atavíos; no obstante, su gesto es esquemático. Parecen haber tenido la función de braseros y se colocaban sobre bases cilíndricas las cuales suelen estar al pie de las escalinatas de los principales edificios de Tehuacán, a manera de adoratorio. ${ }^{86}$

Entre las esculturas de barro, una expresión plástica que ha llamado mi atención por la geometrización y esquematización de sus formas, es un gran brasero con la representación de Tláloc esculpido con gran maestría; actualmente se exhibe en el Museo Nacional de Antropología (fig. 19) ${ }^{87}$ Comparte en alguna medida las cualidades de los xantiles en cuanto al cuerpo cilíndrico, pero es de gran formato. En este brasero, tanto los arillos, como los adornos superiores y laterales del tocado, hechos con la técnica al pastillaje, se forman con círculos perfectos, rectángulos y triángulos con ángulos y líneas rectas; los colmillos aparecen de forma simplificada y esquemática como triángulos alargados y dan más la apariencia de una "barba" que de colmillos. Todas estas cualidades, como hemos visto, son compartidas por el Códice Laud. No está de más comentar que este brasero de gran tamaño tiene, igual que nuestro códice, una relevancia notable respecto a la preeminencia de Tláloc.

84. Noguera también ha encontrado este tipo de figuras en Calipan, en el mismo valle de Tehuacán, cerca de Cozcatlán. Eduardo Noguera, "Excavaciones en Calipan, estado de Puebla", en El México Antiguo, Revista Internacional de Arqueología, t. V (Ciudad de México: Sociedad Alemana Mexicanista, I940-4I), 63-I24.

85. Justamente por la representación de Xochipilli en uno de estos "xantiles" de Tehuacán (Museo Etnológico de Berlín. No. de identificación IV Ca 10957), es que Seler propuso que el Códice Borgia procedía de esta región. Podríamos estar de acuerdo con Seler en la vinculación iconográfica del dios Xochipilli entre el Borgia y el "xantil" de este dios en Tehuacán porque sus atributos y su pintura facial son coincidentes, pero discreparía un poco en afirmar que estos dos tipos de representación tienen un estilo semejante.

86. Noemí Castillo, comunicación personal, 2012.

87. Chadwick y MacNeish, "Codex Borgia The Venta Salada Phase", I23; lo publican como procedente de la zona de Tehuacán y así está indicado en la cédula del MNA, pero curiosamente se exhibe en la sala del Golfo. 
19. Escultura de barro, brasero efigie de Tláloc, Tehuacán, Museo Nacional de Antropología, Ciudad de México. Foto de la autora, 2009. Secretaría de

Cultura-INAH-MÉx. "Reproducción autorizada por el Instituto Nacional de Antropología e Historia”.

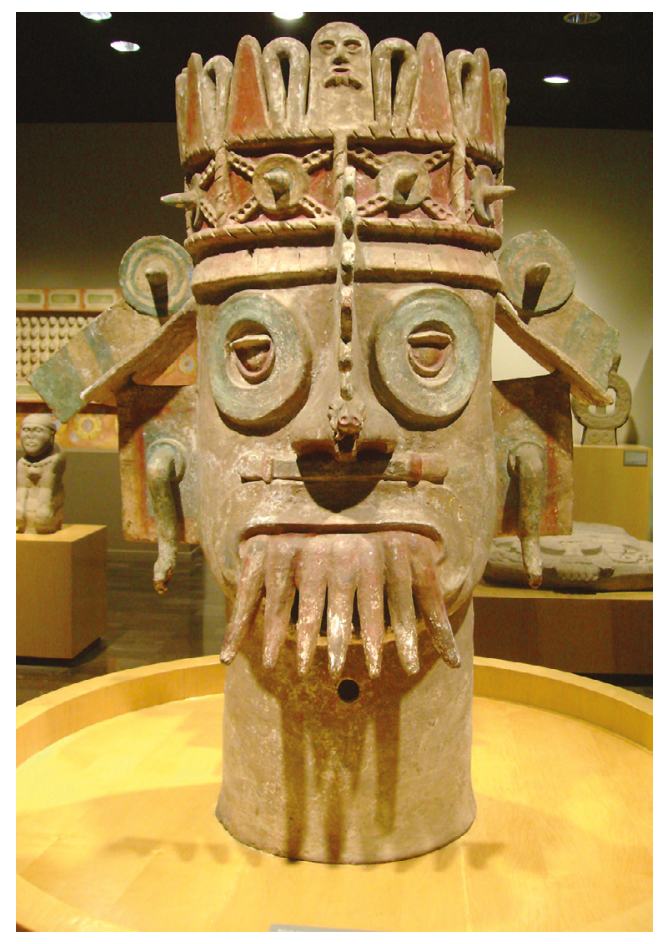

Otra de las expresiones pictóricas de Tehuacán, prácticamente desconocida, es la pintura mural. Fue descubierta hace unas décadas (I99I) por Sisson y Lilly ${ }^{88}$ en una subestructura del asentamiento prehispánico; un antiguo pórtico con dos columnas circulares en la entrada, que fue tapiado en tiempos prehispánicos, encima del cual se construyó otra estructura. En el pórtico están distribuidos siete escudos y parte de un octavo, pues el ala sur de la estructura fue destruida para construir las escaleras de la última etapa constructiva. Por la simetría en que están dispuestos estos escudos, se presume que debieron existir en total nueve ${ }^{89}$ Ninguno de los escudos es igual, pero tienen en común estar formados por círculos y aros delgados perfectamente trazados; lanzas, banderas, cetros, flechas y lanzadardos cruzan a los chimallis en " $\mathrm{x}$ ". En el centro, cada uno tiene símbolos y figuras diferentes; uno con una cabeza humana, identificado como el dios Xipe-Totec, y el resto con formas geométricas, símbolos

88. Sisson y Lilly, "A Codex-Style mural from Tehuacan Viejo, Puebla", 33.

89. Sisson y Lilly, "A Codex-Style mural from Tehuacan Viejo, Puebla", 35. 


\section{DOI: https://doi.org/10.22201/iie.18703062e.2021.118.2745}

que siguen las convenciones de representación de la tradición estilística e iconográfica Mixteca-Puebla. En las columnas se representan también símbolos sacrificiales, corazones y cráneos, que he asociado con los tolteca-chichimeca. ${ }^{90}$

En el registro horizontal inferior, el enlucido de estuco es grueso, bruñido y se dejó como fondo blanco; mientras que el registro superior que abarca la mayor parte del muro, donde están los escudos, tiene un enlucido muy delgado, más como un baño, sobre adobe y sin bruñir, cubierto por completo con un pigmento anaranjado luminoso (fig. 20). Es interesante señalar que este color, el amarillo, y la pintura sobre barro, son cualidades de la pintura mural popoloca del sur de Puebla. En contraste, el azul es más cercano al tono claro "azul cielo" de la tradición tolteca. Así, desde mi punto de vista, las pinturas son muestra de un interesante sincretismo entre las técnicas, los materiales y convenciones plásticas toltecas y popolocas; es decir, en el arte se refleja esa realidad política e histórica que se vivió en Tehuacán.

Dentro de las semejanzas que encuentro entre estas pinturas y el Códice Laud, puedo mencionar que ambas poseen una preferencia por la geometrización y simplificación de las figuras; los círculos son perfectos, las líneas rectas paralelas y perpendiculares crean formas geométricas, cuadrados o rectángulos. También es notable la precisión de la línea, trazada seguramente con instrumentos de apoyo, como reglas y compases (fig. 20). No se aprecian repasos de línea, por lo que su fino grosor es muy uniforme.

Otras semejanzas se aprecian en la forma esquemática y simplificada de representar los símbolos, aunque con matices por el distinto soporte y temática. Las pinturas de Tehuacán tienden en general a las formas geométricas, como en el Laud, pero en ellas el estilo es más sobrio y formal, quizá derivado del tema militar que ostentan. Mientras que en el Laud se puede observar lo que llamaría un naturalismo simplificado, en las pinturas de Tehuacán se puede apreciar un arte más abstracto, esquemático y más rígido.

\section{Conclusiones}

En síntesis, entre el Códice Laud, la pintura mural y la escultura polícroma de Tehuacán hay similitudes en sus rasgos distintivos, como en su preferencia por la geometrización y simplificación de las formas, el uso de instrumentos de apoyo, la composición equilibrada, la precisión de líneas rectas y curvas;

90. Álvarez Icaza, "Variedades estilísticas de la tradición Mixteca-Puebla", I82. 


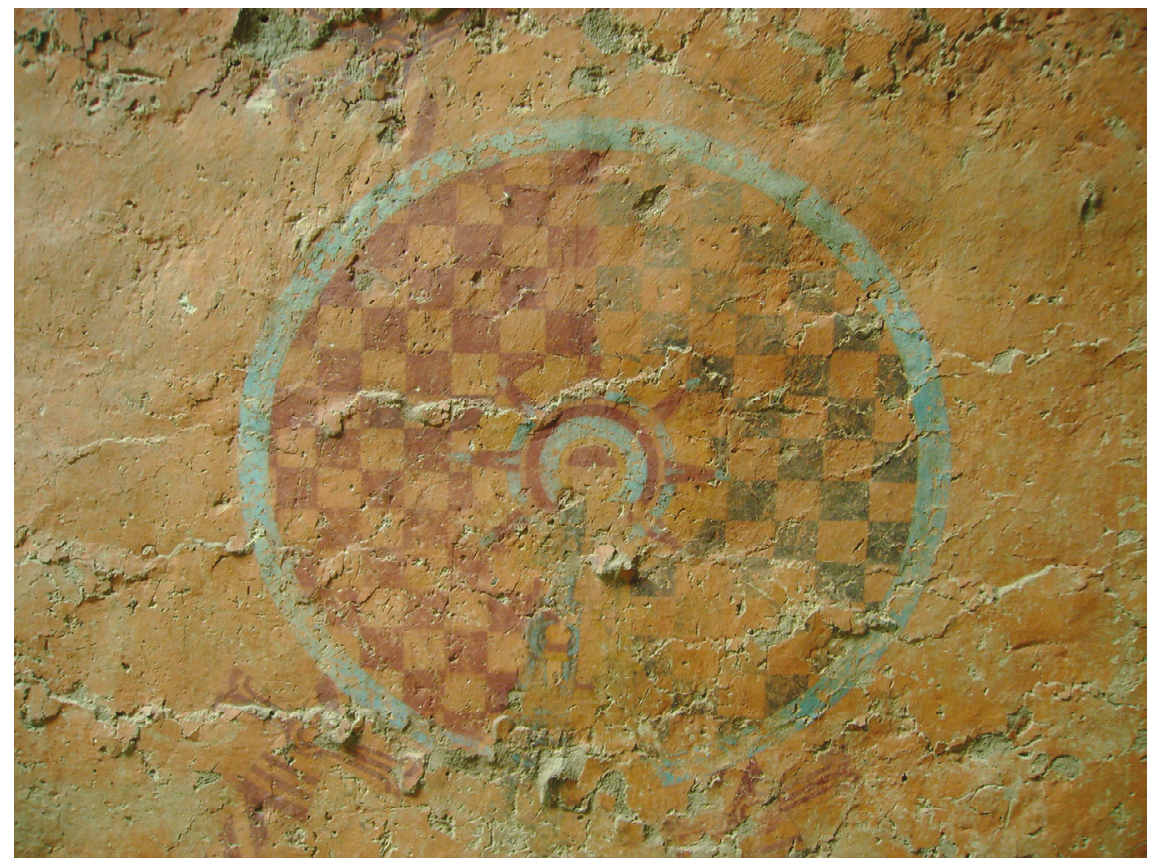

20. Pintura mural de Tehuacán, Puebla. Foto de la autora, 20II, detalle.

así como en la representación de valores táctiles, puesto que en general ambos tienen un estilo plano y esquemático. Estas similitudes justo contrastan con el estilo del Borgia y del valle de Puebla-Tlaxcala, en donde hay un predominio en la representación detallada de texturas.

Por tanto, afirmar que el Códice Laud y el Fejérváry-Mayer provienen del valle de Tehuacán, con base en las evidencias analizadas, es la hipótesis más fuerte. El valle estaba habitado en el Posclásico Tardío por grupos nahuas y es un triángulo formado hacia el Golfo y la Mixteca que permitió a sus pobladores tener vínculos con ambas zonas y a sus artistas elaborar obras que comparten cualidades estilísticas e iconográficas. Quedan pendientes para un estudio posterior las pinturas de Cozcatlán, pues sus imágenes zoomorfas recuerdan al estilo simplificado del Códice Laud.

Las fuentes históricas, la arqueología, la lingüística y las herramientas propias de la historia del arte, como el estudio comparativo que se presentó de manera sucinta aquí, aportan datos para proponer a los tolteca nonoalcas, 


\section{DOI: https://doi.org/10.22201/iie.18703062e.2021.118.2745}

de cultura náhuatl, como los posibles creadores del Códice Laud y del Fejérváry-Mayer. Muy posiblemente estos tolteca nonoalcas tenían relaciones comerciales, a través del Golfo, con el área maya, en especial con los itzaes; de ahí las semejanzas iconográficas con Ek’Chuak y el Fejérváry, y razón por la cual se ha ligado a este códice con comerciantes.

El Códice Borgia, seguramente, proviene del valle de Puebla-Tlaxcala, de Cholula, y hay diversas manifestaciones plásticas que ayudan a identificar una escuela pictórica con raigambre histórica, fuerte y definida en esta región. La investigación realizada en torno al problema de la procedencia del Códice Laud, como sabemos, no es un problema privativo de él, sino que involucra a todos los códices del Grupo Borgia. Al hacer el estudio puntual se pudieron identificar algunas cualidades estilísticas que definen los códices, la pintura mural y la alfarería de seis diferentes regiones, que si bien poseen cualidades comunes de la tradición Mixteca-Puebla, expresan particularidades que podrían apuntar hacia la existencia de escuelas pictóricas, relacionadas incluso con las fronteras políticas de los señoríos.

Asimismo, el repertorio iconográfico nos habla de una dominación ideológica de unos grupos sobre otros. La investigación también muestra la utilidad de los estudios comparativos que abordan la iconografía y el estudio del estilo del arte mesoamericano, para contribuir en la determinación de la temporalidad, espacio y agentes involucrados en la creación de estos documentos; lo que permite emplear estas fuentes de información de primera mano, no sólo para conocer la religiosidad y cosmovisión, sino la historia cultural y política de quienes nos antecedieron. \&

N.B. Agradezco a Pablo Escalante Gonzalbo, Erik Velásquez, Marie Areti Hers, Guilhem Olivier, José Luis Ruvalcaba, Annick Daneels, Renato González Mello, Saeko Yanagisawa, Diana Magaloni, Carlos Marínez Marín, Sonia Lombardo, Teresa Uriarte, Noemí Castillo, Marco Antonio Tovar, Miguel Ángel Gasca, Martha Carmona, Bertina Olmedo, Alessandra Russo, Bruce Barker-Benfield, Sallyanne Gilchrist Virginia Lladó, Marinita Siglitz, Joanna Ostapkowicz, Ann Stuart, Keith Oliver, Siobhan Watts, Élodie Dupey, Davide Domenici y Antonio Sgamellotti. unam, Posgrado en Historia del Arte, Proyecto Papiit No. 402012, Proyecto Pintura Mural Prehispánica. Museo Nacional de Antropología, Biblioteca Nacional de Antropología e Historia, Consejo de Arqueología, InAH. Conacyt, México. Biblioteca Bodleiana, Taller de Conservación, Universidad de Oxford. World Museum of Liverpool. Biblioteca de la Asamblea Nacional de Francia y a la Biblioteca Nacional de Francia. 